\title{
Development and Evaluation of
} A Comprehensive Program to Reduce Drinking and Impaired Driving Among College Students

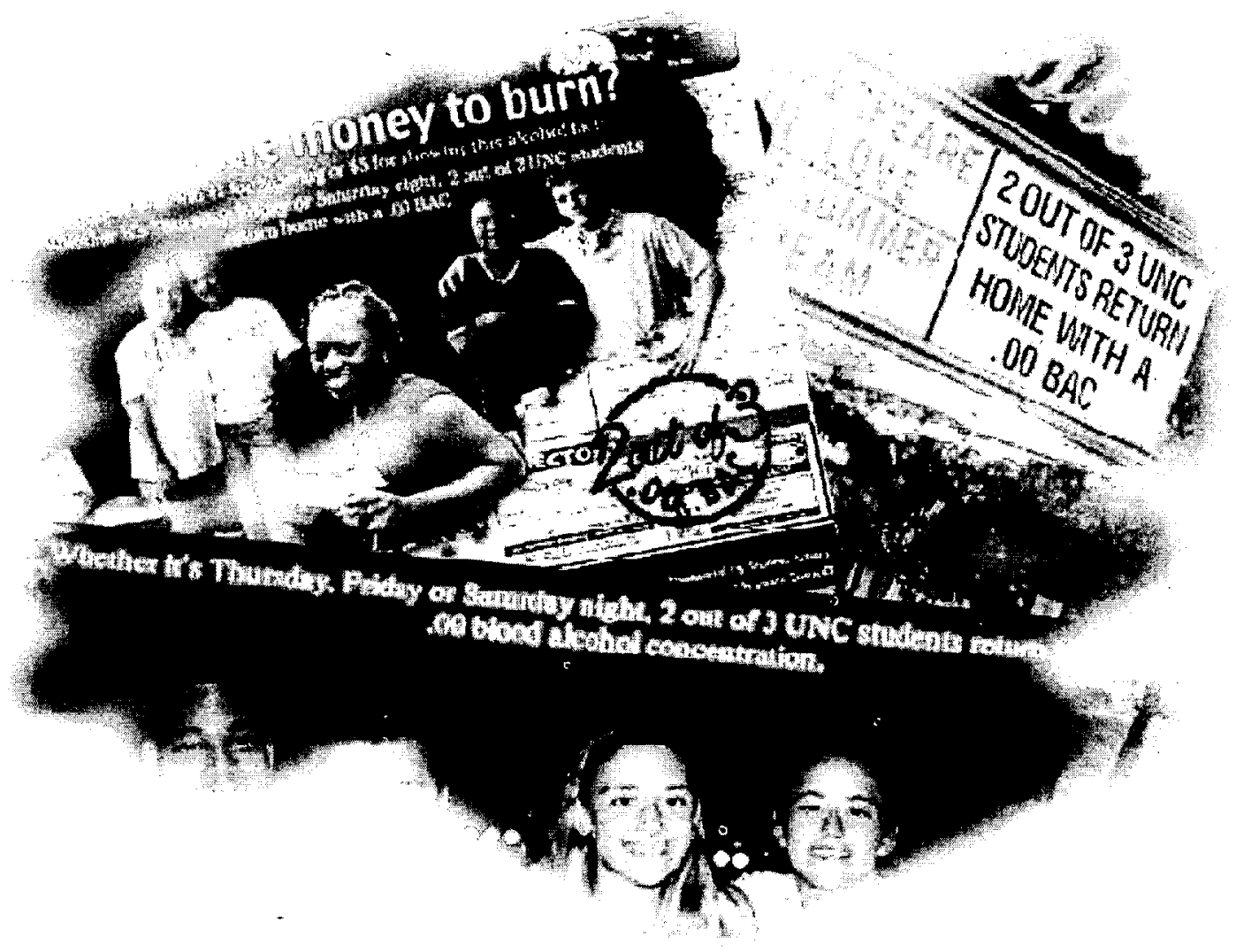


This publication is distributed by the U.S. Department of Transportation, National Highway Traffic Safety Administration, in the interest of information exchange. The opinions, findings and conclusions expressed in this publication are those of the author(s) and not necessarily those of the Department of Transportation or the National Highway Traffic Safety Administration. The United States Government assumes no liability for its content or use thereof. If trade or manufacturer's names or products are mentioned, it is because they are considered essential to the object of the publication and should not be construed as an endorsement. The United States Government does not endorse products or manufacturers. 


\begin{tabular}{|c|c|c|}
\hline $\begin{array}{l}\text { 1. Report No. } \\
\text { DOT HS } 809396\end{array}$ & 2. Government Accession No. & 3. Recipient's Catalog No. \\
\hline \multirow{3}{*}{\multicolumn{2}{|c|}{$\begin{array}{l}\text { 4. Title and Subtitle } \\
\text { Development and Evaluation of A Comprehensive Program to } \\
\text { Reduce Drinking and Impaired Driving Among College Students }\end{array}$}} & 5. Report Date \\
\hline & & January 2001 \\
\hline & & 6. Performing Organization Code \\
\hline \multicolumn{2}{|c|}{$\begin{array}{l}\text { 7. Author(s) } \\
\text { Robert D. Foss, Lauren J. Marchetti, \& } \\
\text { Kathleen A. Holladay. }\end{array}$} & 8. Performing Organization Report No. \\
\hline \multicolumn{2}{|l|}{ 9. Performing Organization Name and Address } & 10. Work Unit No. (TRAIS) \\
\hline \multirow{2}{*}{\multicolumn{2}{|c|}{$\begin{array}{l}\text { University of North Carolina } \\
\text { Highway Safety Research Center } \\
730 \text { Airport Road, CB \#3430 } \\
\text { Chapel Hill, NC } 27599-3430\end{array}$}} & \\
\hline & & $\begin{array}{l}\text { 11. Contract or Grant No. } \\
\text { DTHN22-97-H-05120 }\end{array}$ \\
\hline \multirow{3}{*}{\multicolumn{2}{|c|}{$\begin{array}{l}\text { 12. Sponsoring Agency Name and Address } \\
\text { US Department of Transportation } \\
\text { National Highway Traffic Safety Administration } \\
\text { Washington, DC } 20590\end{array}$}} & 13. Type of Report and Period Covered \\
\hline & & Final Report, 7/1997 - 1/2001 \\
\hline & & 14. Sponsoring Agency Code \\
\hline
\end{tabular}

15. Supplementary Notes

16. Abstract

This report describes the development of a program to reduce drinking on a college campus. The ultimate goal of the program is to reduce motor vehicle crashes resulting from driving after drinking, as well as other health and social problems that result from alcohol consumption by young persons in a university environment. To understand student drinking this project employed a unique approach: a nighttime survey in which randomly selected students provided breath samples that allowed measurement of their blood alcohol concentration (BAC). During the fall of 1997, BAC measurements were obtained from 1,786 students as they returned home between 10 p.m. and 3 a.m. Although $23 \%$ of students had been drinking, high BACs were relatively uncommon. Eleven percent of students had a BAC above .08 and less than $2 \%$ were above .15. Even on traditional "party nights," (Thursday through Saturday), $65 \%$ of students returned home with a $.00 \mathrm{BAC}$. Through a series of discussions with students, a basic message was developed that was clear and easily understood by students: "Whether it's Thursday, Friday, or Saturday night, 2 out of 3 UNC students return home with a $.00 \mathrm{BAC}$." A comprehensive program was developed to deliver this message to the student community. The BAC survey was repeated during the fall of 1999 . Information about awareness and understanding of the " 2 out of 3" program was obtained from the sample of 2,535 students. Seventy-one percent of students and $92 \%$ of first year students were aware of the program. Among those who had heard of the program, $70 \%$ understood the fact to mean that drinking is less common or that pressure to drink is less than is typically believed. The proportion of students with a BAC above .08 declined from $10.7 \%$ to $8.3 \%$, a statistically significant decline of $22 \%$. Student incidents involving alcohol also declined in association with the "2 out of 3" program. However, self-reported drinking, as typically measured, did not change from the earlier survey.

\begin{tabular}{l|l}
\hline 17. Key Words: & 18. Distribution Statement
\end{tabular}

Behavioral norms, Blood Alcohol Concentration (BAC), College Student, Underage Drinking, Prevention, DWI 


\section{Acknowledgements}

We greatly appreciate the foresight and commitment of the late Chancellor Michael Hooker and the wholehearted support of key officials at the University of North Carolina at Chapel Hill. They are too numerous to mention individually, but we owe a special debt, and wish to express our extreme gratitude, to Dr. Susan Kitchen, Vice Chancellor for Student Affairs, Dr. Melissa Exum, Dean of Students and the staff at the UNC Center for Healthy Student Behaviors.

We also wish to express our appreciation to Bill Tolbert, Paige Perriello, and Chad Sattler who played crucial roles in the development of this project, and to Chris Bartley, Alison Burke, Sherrie Hart, Kelly Ritch, James Schatz, and Kurt Scholla, who served as data collection team supervisors. We also offer our thanks and great appreciation to the more than three dozen individuals who served as interviewers for the two rounds of BAC data collection.

This research was supported in part by the National Highway Traffic Safety Administration (NHTSA), U.S. Department of Transportation, under Contract No. DTHN22-97-H-05120, the North Carolina Governor's Highway Safety Program (GHSP; Contract Nos. YA-97-04-04, YA-98-04-04, AL-99-02-09), and the UNC - Chapel Hill Office of Student Affairs. The opinions, findings, and recommendations contained herein are those of the authors, and do not necessarily represent those of the NHTSA, NC GHSP or the University of North Carolina. 


\section{TABLE OF CONTENTS}

Page

1. Introduction \& Background $\ldots \ldots \ldots \ldots \ldots \ldots \ldots \ldots \ldots \ldots \ldots \ldots \ldots \ldots \ldots \ldots$

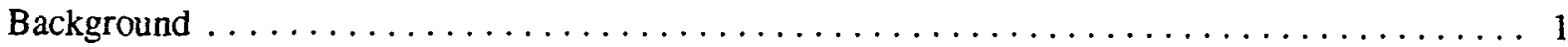

Measurement Issues Concerning Student Alcohol Use $\ldots \ldots \ldots \ldots \ldots \ldots \ldots \ldots \ldots \ldots \ldots 2$

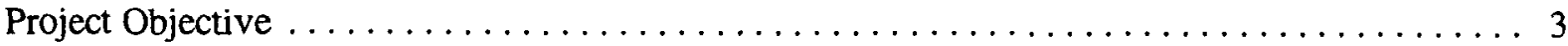

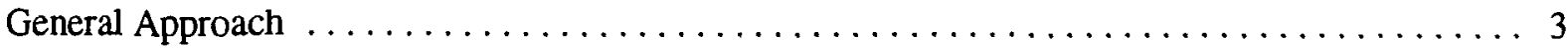

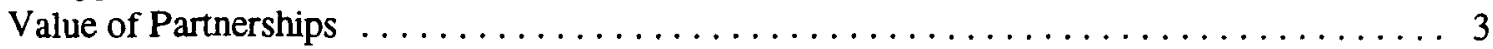

2. Baseline and Problem Identification Survey $\ldots \ldots \ldots \ldots \ldots \ldots \ldots \ldots \ldots \ldots \ldots \ldots$

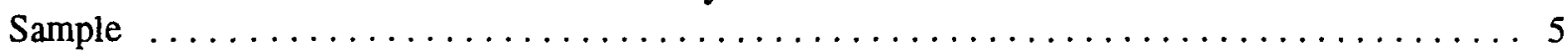

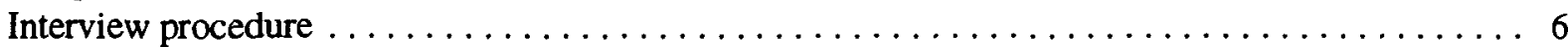

Dealing with students thought to be at risk due to excessive alcohol consumption $\ldots \ldots \ldots 7$

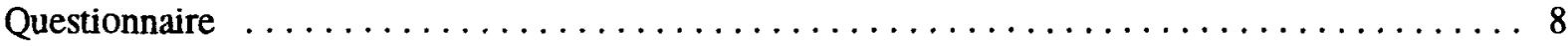

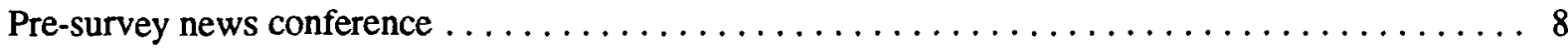

Concerns and cooperation of university officials $\ldots \ldots \ldots \ldots \ldots \ldots \ldots \ldots \ldots \ldots \ldots$

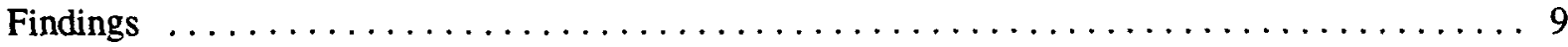

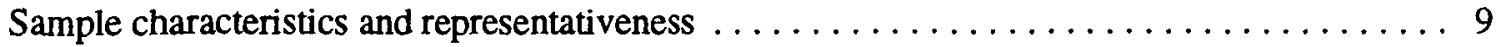

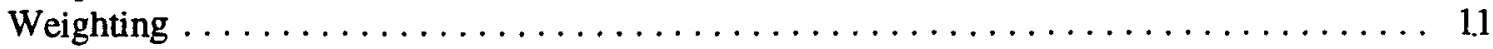

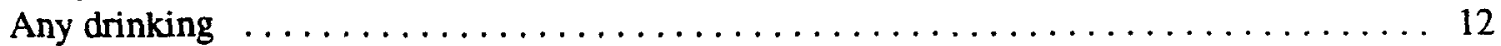

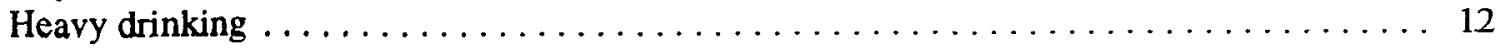

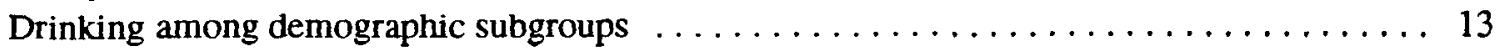

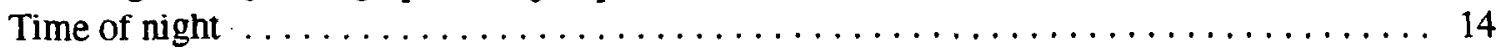

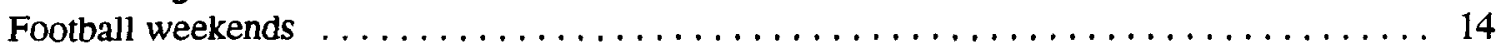

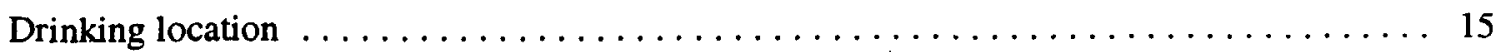

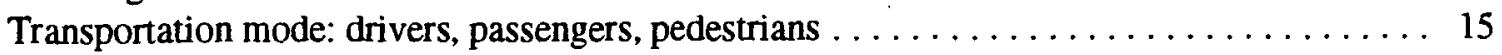

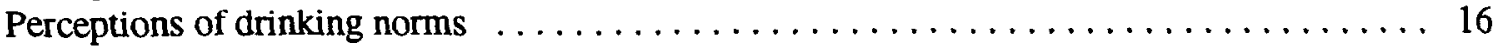

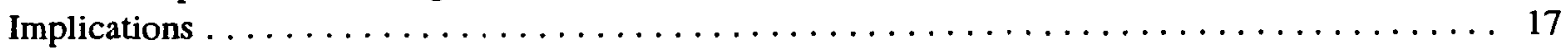

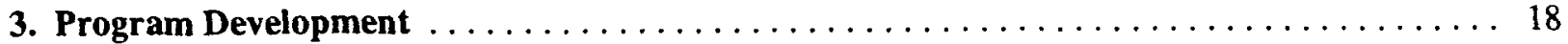

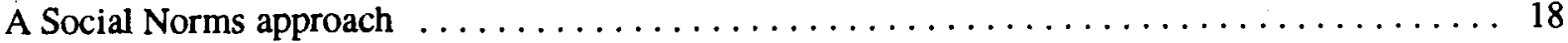

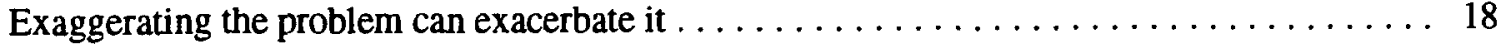

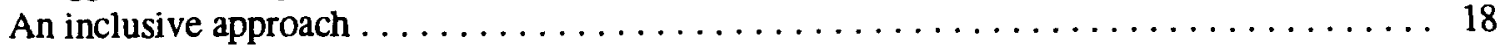

Development of the UNC-CH " 2 out of 3 " program $\ldots \ldots \ldots \ldots \ldots \ldots \ldots \ldots \ldots \ldots \ldots$

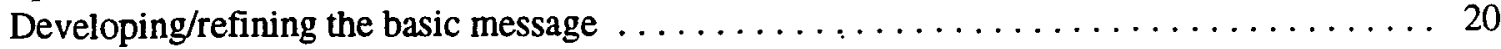

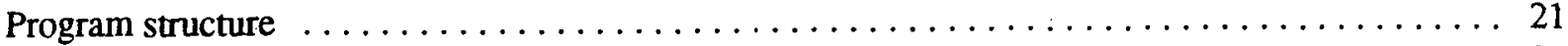

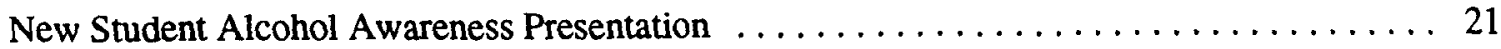

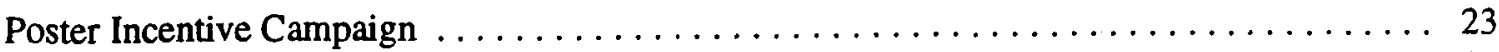

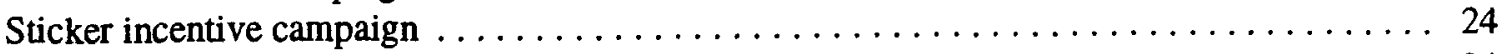

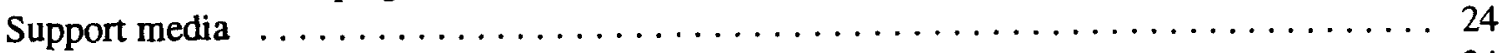

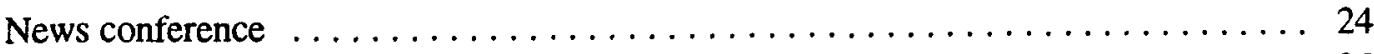

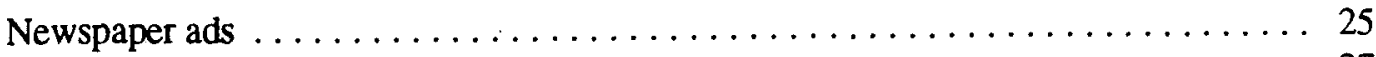

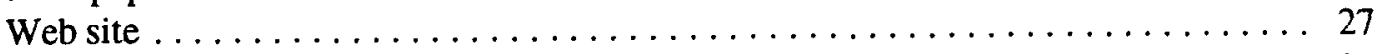

Impact of data collection activities on awareness $\ldots \ldots \ldots \ldots \ldots \ldots \ldots \ldots \ldots \ldots \ldots$

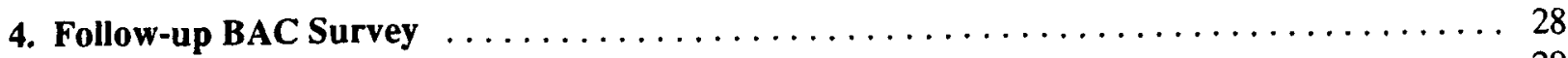

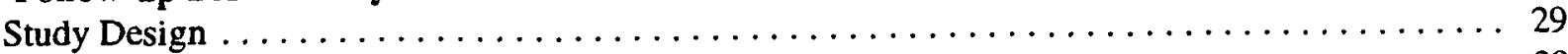

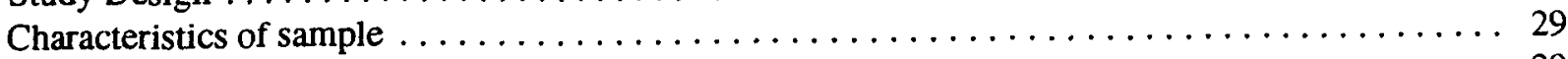

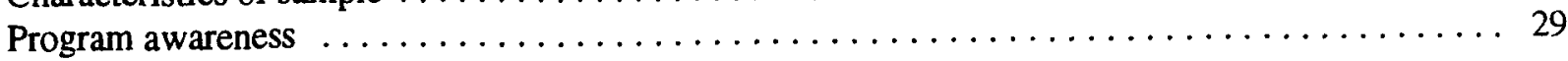




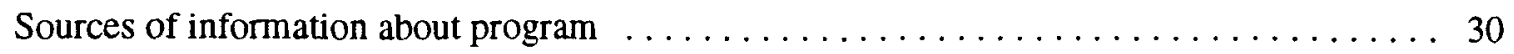

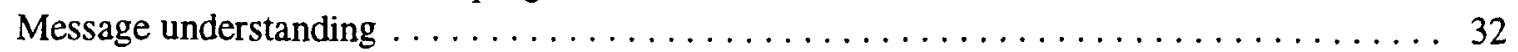

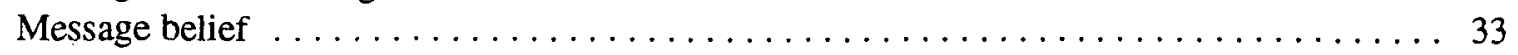

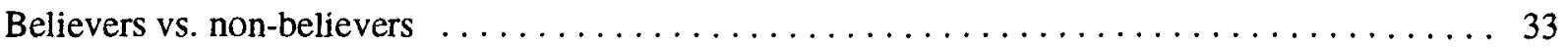

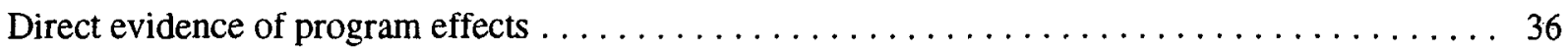

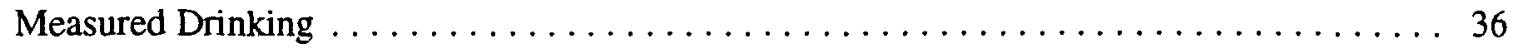

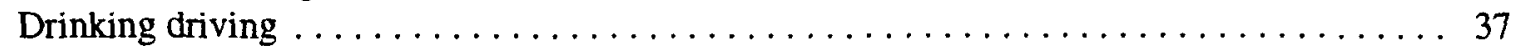

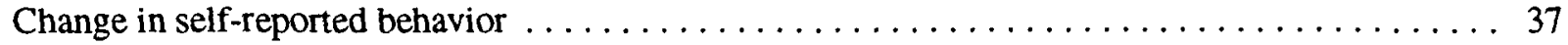

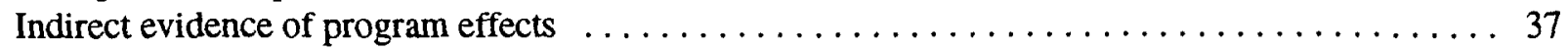

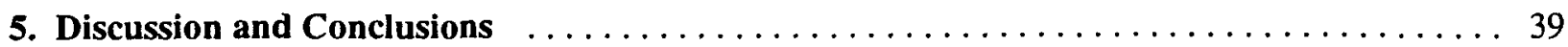

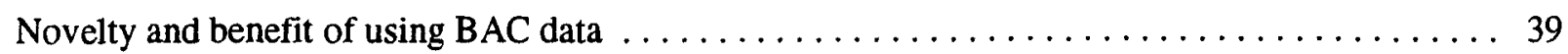

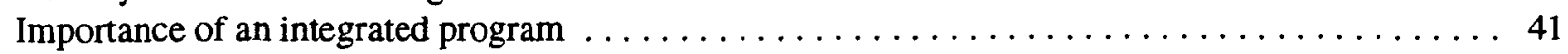

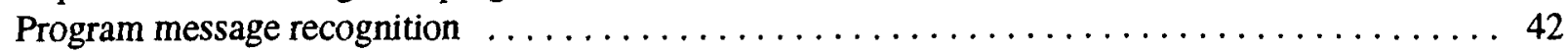

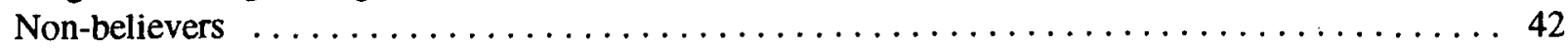

Addressing the fact that drinking for many college students is illegal $\ldots \ldots \ldots \ldots \ldots \ldots \ldots$

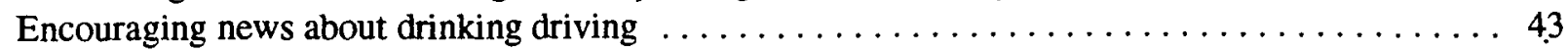

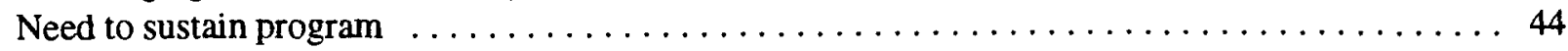

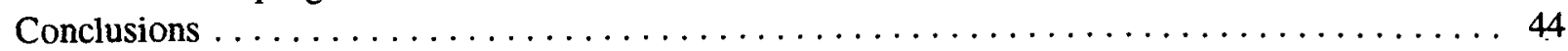

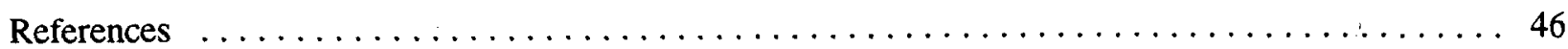

Appendix 2.a. 1997 Interview Questionnaire

Appendix 4.a. 1999 Interview Questionnaire 


\section{LIST OF TABLES}

Page

Table 2.1 Demographic characteristics of survey sample compared with student population

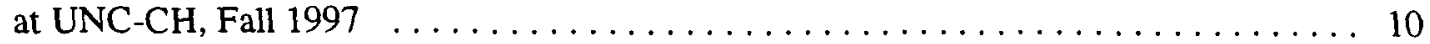

Table 2.2 Blood alcohol concentration of students by time of week (percent) $\ldots \ldots \ldots \ldots \ldots$

Table 2.3 BAC distribution for "binge" drinkers* $\ldots \ldots \ldots \ldots \ldots \ldots \ldots \ldots \ldots \ldots \ldots$

Table 2.4 Proportion of respondents with BAC above three thresholds on football

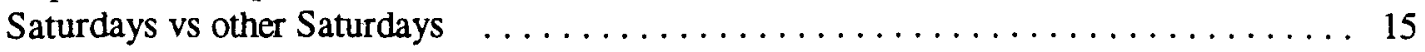

Table 2.5 Percent of respondents with BAC above .00 and .08 by mode of arrival $\ldots \ldots \ldots 16$

Table 4.1 Timeline for "2 out of 3" Project $\ldots \ldots \ldots \ldots \ldots \ldots \ldots \ldots \ldots \ldots \ldots \ldots \ldots \ldots$

Table 4.2 Characteristics of 1997 and 1999 samples (percent) $\ldots \ldots \ldots \ldots \ldots \ldots \ldots \ldots$

Table 4.3 Source of information about " 2 out of 3 " fact by class year (percent) $\ldots \ldots \ldots \ldots \ldots 31$

Table 4.4 Percent of respondents with BAC above three thresholds $\ldots \ldots \ldots \ldots \ldots \ldots \ldots \ldots$

Table 4.5 Number of alcohol-related student incidents reported to university authorities $\ldots \ldots \ldots 38$ 


\section{LIST OF FIGURES}

Page

Figure 2.1 Diagram of on-campus routes followed by data collection teams $\ldots \ldots \ldots \ldots \ldots$

Figure 2.2 Proportion of students with BACs above three thresholds by time of night $\ldots \ldots \ldots 14$

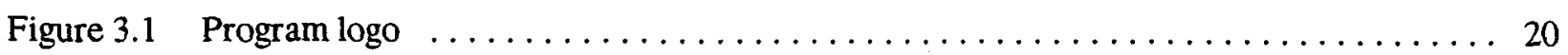

Figure 3.2 Clip from video showing students being intervieweed about drinking at UNC-CH $\ldots \ldots 21$

Figure 3.3 Interactive demonstration of the " 2 out of 3" fact at new student orientation session ... 22

Figure 3.4 Card handed to students and parents as a reminder of the " 2 out of 3 " fact $\ldots \ldots \ldots 22$

Figure 3.5 Poster displayed in common areas of residence halls $\ldots \ldots \ldots \ldots \ldots \ldots \ldots$

Figure 3.6 Poster distributed to individual student rooms in freshman residence halls $\ldots \ldots \ldots 24$

Figure 3.7 Sticker distributed at various campus locations $\ldots \ldots \ldots \ldots \ldots \ldots \ldots \ldots \ldots$

Figure 3.8 First student newspaper advertisement $\ldots \ldots \ldots \ldots \ldots \ldots \ldots \ldots \ldots \ldots \ldots$

Figure 3.9 Second student newspaper advertisement $\ldots \ldots \ldots \ldots \ldots \ldots \ldots \ldots \ldots \ldots \ldots \ldots$

Figure 3.10 Third student newspaper advertisement $\ldots \ldots \ldots \ldots \ldots \ldots \ldots \ldots \ldots \ldots \ldots$

Figure 3.11 Screen shot from web site showing feedback made available to students about the

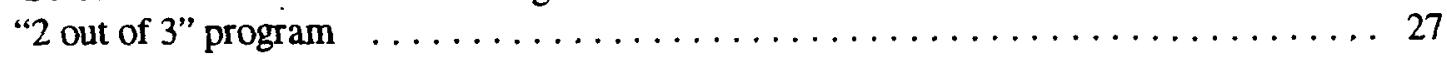

Figure 4.1 Non-belief in Accuracy of " 2 out of 3" by Number of Drinking and Heavy Drinking

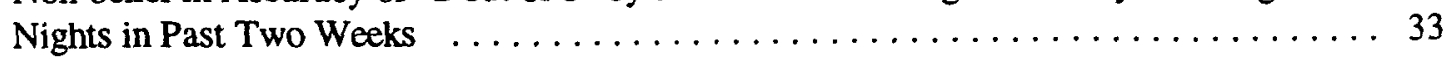

Figure 4.2 BAC distributions comparing those who believed the "2 out of 3 " fact was accurate with

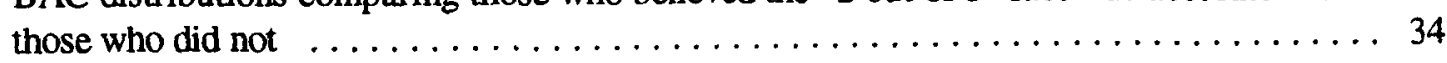

Figure 4.3 Student newspaper ad to provide feedback to students about results of 1999 BAC survey . 35 


\section{Executive Summary}

This report describes the development of a program to reduce drinking on a college campus. The program combines student blood alcohol concentration (BAC) data with a social norms approach. The ultimate goal of the program is to reduce motor vehicle crashes resulting from driving after drinking, as well as other health and social problems that result from alcohol consumption by young persons in a university environment.

During the 1990s several national surveys documented that drinking is widespread among college students in the United States. These surveys and a number of other studies also documented a wide variety of undesirable consequences of student drinking. In addition to deaths and injuries resulting from motor vehicle crashes, college students increase their risk of injury as pedestrians, in falls and in fires. Alcohol use also contributes to interpersonal violence, including sexual assault, and academic problems. Despite this, relatively little is known about student drinking and few programs to ameliorate drinking and its consequences have been evaluated.

To gain a clearer picture of student drinking on one university campus this project employed a unique approach: a nighttime survey in which randomly selected students provided breath samples that allowed measurement of their blood alcohol concentration. During the fall of 1997, BAC measurements were obtained from 1,786 students as they returned home to residence halls, fraternity and sorority houses and off-campus apartments between 10 p.m. and 3 a.m.

By focusing on nightly drinking and using a direct measurement as an indication of amount of drinking, a somewhat different picture of student alcohol use emerged than is revealed by self-report surveys. Although $23 \%$ of students had been drinking, high BACs were relatively uncommon. Eleven percent of students had a BAC above .08 and less than $2 \%$ were above .15. Of particular note is that even on traditional "party nights," (Thursday through Saturday), 65\% of students returned home with a .00 BAC.

Research has found that students overestimate the amount of drinking on college. Evidence of this misperception about the amount of drinking was found in the present study as well. Consequently, a program was developed that drew on findings from the BAC survey to help students recognize the reality of drinking on their campus. This "social norms" approach to drinking on college campuses has shown great promise for reducing excessive student drinking. This is the first time a norms program has been able to provide students with concrete information about drinking based on BAC measurements.

Through a series of discussions with students, a basic message was developed that was clear and easily understood by students: "Whether it's Thursday, Friday, or Saturday night, 2 out of 3 UNC students return home with a .00 BAC." A comprehensive program was developed to deliver this message to students through several channels and to encourage them to remember it. The program focused initially on 
first year students who are just finding their "niche" on campus in hopes of preventing them from developing the same misperceptions about drinking that characterize older students.

This information about the true alcohol use "norm"was delivered directly to all incoming students and their parents at orientation sessions. In addition, it was delivered to the entire student population through an incentive campaign involving posters and stickers, and through a media plan. By displaying posters and stickers or by knowing the " 2 out of 3" alcohol fact, students had a chance to win cash. A news conference spread the message throughout the campus community and beyond. Periodic ads in the student newspaper drew attention to both the normative fact and the incentive program.

The BAC survey was repeated during the fall of 1999. In addition to measuring student alcohol use again, information about awareness and understanding of the "2 out of 3" program was obtained from the sample of 2,535 students. Seventy-one percent of students and 92\% of first year students were aware of the program. Among those who had heard of the program, $70 \%$ understood the fact to mean that drinking is less common or that pressure to drink is less than is typically believed. Understanding was also higher among first year students ( $78 \%$ vs. $64 \%$ of older students). However, a substantial proportion of students $(54 \%)$ did not believe the " 2 out of 3 " fact accurately portrayed student drinking. This skepticism about a fact that goes counter to common belief was not unexpected, and will need to be addressed as the program . continues. The skepticism may be another indicator of the widespread existence of misperceptions about college student drinking and reinforces the need for further research on programs designed to counter these misperceptions.

Analyses of the BAC measurements indicate that drinking has declined somewhat since the earlier survey. The proportion of students with a BAC above .08 declined from $10.7 \%$ to $8.3 \%$, a statistically significant decline of $22 \%$. Student incidents involving alcohol also declined in association with the " 2 out of 3" program. However, self-reported drinking, as typically measured, did not change from the earlier survey.

It will require a sustained effort over several years to develop a thorough and accurate understanding of normative levels of alcohol use among students. It is clear, however, that there are a number of benefits of using BAC data rather than simple self-reports of drinking as the source of data for a normative information program. Apparently because of the simplicity of the message and the multi-faceted nature of the " 2 out of 3 " program, both awareness and understanding of this program were found to be high. The prevalence of heavier drinking has declined as well. Additional monitoring of student alcohol use will be necessary to assess the ultimate potential of a long-term BAC-based social norms campaign. 


\section{Introduction \& Background}

The project described in this report was conducted at the University of North Carolina at Chapel Hill (UNC-CH). Like many university communities, UNC-CH has experienced alcohol-related deaths and injuries during the past several years and much attention has been focused on alcohol issues. This project examined the nature of student drinking at $\mathrm{UNC}-\mathrm{CH}$, then used that information to develop and evaluate a program designed to dispel the common misperceptions about drinking by students. A unique feature of this project was the collection of voluntary breath measurements from students returning to their residences late at night. These data provided the core information for a program designed to help students realize that drinking less common than many think. While the overriding concern alcohol poses to highway safety professionals is alcohol-related motor vehicle crashes, strategies that address the problem of alcohol impairment in general can reduce the tragic consequences of drinking and driving while also reducing other alcoholrelated injuries and deaths.

... strategies that address the problem of alcohol impairment in general can reduce the tragic consequences of drinking and driving while also reducing other alcoholrelated injuries and deaths.

The program that was developed and implemented is not intended to stand alone. It is designed to serve as an important component in a comprehensive campus alcohol program. It is hoped that, in conjunction with the variety of other programs on campus that support healthy behaviors and wise choices, this program will help to prevent future tragedies.

\section{Background}

A 1997 national survey of students from 130 U.S. colleges \& universities found, based on selfreport, that 43 percent of students had consumed either five drinks (males) or four drinks (females) on a single occasion during the past two weeks. These persons are typically labeled as 'heavy episodic' or 'binge' drinkers (Wechsler et al., 1998). Twenty-one percent were frequent 'heavy episodic' drinkers (five/four drinks on an occasion three or more times in the past two weeks). This four-year follow-up of a similar 1993 survey (Wechsler et al., 1994) found few changes in student drinking, but did detect increases in consequences associated with drinking and motivations for drinking. A repeat of this survey in 1999 covering 119 campuses detected both encouraging and discouraging changes, with a greater proportion of abstainers, but also more of the heaviest drinkers (Wechsler, et al., 2000). 
Excessive consumption of alcohol by college students exposes them to a variety of risks. In addition to the risks of driving after drinking (Sleet, Wagenaar, \& Waller, 1989; National Highway Traffic Saftey Administration, 1999), students also experience increased risk of injury as pedestrians and bicyclists, and as the result of falls and fires (Hingson \& Howland, 1993). Heavy drinking is associated with greater probabilities of sexual assault, health problems, unsafe and unplanned sexual activity, sexual harassment, impaired sleep and study time, and interpersonal problems (Presley, Meilman \& Lyerla, 1997, Roizen, 1997; Harrington \& Leitenberg, 1994). Alcohol use is commonly involved in a variety of unintentional injuries, including drowning (Smith et al., 1999), suicide, homicide (Goodman et al., 1991) and injuries resulting from interpersonal violence (Martin, 1992). Because of the prevalence on college campuses of old multi-story buildings, especially residence halls, falls from windows, off buildings and down stairwells are a common cause of death and injury for college students. Excessive drinking is often a contributing factor in fall-related death and injury (Hingson \& Howland, 1993). UNC-CH in recent years has experienced the death of an impaired student who ran into the side of a moving vehicle, and student deaths from alcohol-related falls and fires, tragedies that galvanized the resolve to address student drinking. Clearly, alcohol is a serious problem at UNC-CH and college campuses everywhere. As campuses attempt to address this problem, it is important to better understand actual alcohol use by students.

\section{Measurement Issues Concerning Student Alcohol Use}

A number of recent studies have examined self-reported drinking behavior among college students, but these studies present an incomplete picture of the phenomenon. Although reports of having five drinks on an occasion - a commonly used measure -- clearly indicate atypically heavy drinking, which is associated with a variety of problems, this is an imprecise measure. For example, consumption of four drinks by a small inexperienced female drinker, during a one-hour period would produce a substantially higher BAC and greater impairment than that same amount consumed over the course of an entire evening by a large, experienced male drinker. Despite this shortcoming, almost no data have been collected that reveal degree of impairment or blood alcohol concentration (BAC) levels reached when students drink

With the exception of experimental work, collection of actual impairment (BAC) data has been limited aimost exclusively to roadside surveys of drivers (Foss \& Beirness, 1996; Voas et al., 1998). To our knowledge only two other research teams have obtained BAC data in surveys of college students. Both of these involved non-random samples obtained near drinking establishments. In 1988 Werch et al. obtained BAC measurements from individuals outside bars adjacent to a university campus, although respondents' student status was not determined. More recently Glindeman et al. (1998) measured BACs for nearly 1,600 individuals along a commercial strip adjacent to a large university ( $83 \%$ of whom were students) over a three year period. This was an intervention designed to provide BAC information to pedestrians, rather than an attempt to obtain information from a representative sample. Nonetheless, the data did allow some objective examination of the nature of student drinking. Among the noteworthy findings was that results from objective BAC measurement were somewhat at variance with findings from self-report surveys. This further emphasizes the need for improved measurement of student alcohol use.

The present study was conducted to develop a more complete understanding of student alcohol use on one campus, to support development of a program to reduce excessive or dangerous alcohol use. The 
several shortcomings of simple retro counts of drinking in response to closed-end survey questions led us to seek an alternati isurement. Concerns about whether individuals actually count (and remember) the number of drinks they have, the decreased likelihood of accurate counting and/or recall as one becomes impaired, difficulties with the notion of a 'standard' drink especially for individuals who often consume beer from containers of decidedly non-standard size (combined with varying alcohol content in different drinks even given equivalent volume) all point to the need for an additional approach to measuring student drinking. Direct BAC measurement provides a highly desirable adjunct to selfreports of drinking, especially when assessing the effects of interventions. In the present study, which we believe is the first of its kind, we combined responses to typical survey questions, with a direct measurement of $\mathrm{BAC}$.

\section{Project Objective}

The goal of this project is to examine the nature of student drinking behavior at UNC-Chapel Hill then to develop and evaluate a comprehensive program designed to ameliorate the problems of excessive drinking and driving (or walking or riding a bicycle) while impaired among this population. As a distinguishing feature of this project, voluntary breath measurements obtained from a representative sample of students were used to enhance our understanding of alcohol use on this campus. This information, in conjunction with responses to a brief interview, provided useful information and insights about the nature of college student drinking behavior as we developed a comprehensive program. This unique information also became an integral part of the program.

\section{General Approach}

From the beginning, this project reflected a "Safe Communities" approach, wherein various groups and organizations within and external to the community form partnerships, bringing their unique resources together, to address a problem. The traditional means of identification of the alcohol problem (selfreported survey data, crash and alcohol-related incident data) was augmented with the voluntary breath measurement data (collected at night as students returned to their places of residences). Since analysis of the data indicated a large discrepancy between perceived and actual consumption of alcohol by students, a year-long information program using the social norms approach was developed. This program included incentive campaigns through which students were rewarded for knowing or displaying the accurate alcohol facts. The primary evaluation of this program was a repeat of the breath measurement survey.

\section{Value of Partnerships}

Having several partners was particularly valuable to this project's ability to perform a variety of tasks. Each brought the kinds of resources that they are uniquely suited to provide. The North Carolina Governor's Highway Safety Program provided the initial support to explore the feasibility of doing a project in which a college campus was treated as a community, and provided the funding for the collection of the survey data. As the scope of the project grew into one that held promise to become a national model, using a unique approach to data collection on a large campus with a national reputation, the National Highway Traffic Safety Administration provided the funding needed to expand the project. The 
University provided the funds for the incentive programs and the placement of advertisements in the campus newspaper.

The implementation of the program was accomplished through several units and constituencies of the University working together with the Highway Safety Research Center (HSRC). Among the various players from the University were the Vice Chancellor for Student Affairs, the Dean of Students, individuals from the Center for Healthy Student Behaviors, the University housing office, including the Director and residence hall staff, representatives of student government including several student body presidents, representatives of the Greek community including the Director of Greek Affairs and presidents of the Interfraternity and Panhellenic Councils, the University Parents Council (who provided financial support for parts of the program), and the University Office of News Services. Without any one of these parties, the project could not have been done. 


\section{Baseline and Problem}

\section{Identification Survey}

The initial step in the project was to conduct a representative survey of students in which a blood alcohol concentration (BAC) measurement would be obtained in conjunction with self-report information. The purpose of this initial survey was to (1) establish a baseline of alcohol use against which future, postprogram measurements could be compared and (2) identify the nature and scope of student drinking, looking for particular problem areas that might productively be targeted by an intervention. As mentioned above, relatively little is known about students' behaviors in association with drinking. It was our hope to gain a better understanding of this phenomenon on this campus prior to developing a program to ameliorate problems.

\section{Sample}

The sampling procedure was designed to obtain a representative sample of students who were returning home in the evening. It was reasoned that the one place we would most likely be able to sample from the entire student population would be as they returned home since that is the one place that virtually all students go at some point during an evening.

The campus was divided into four geographically distinct routes along which interview teams walked. These routes passed by every residence hall, fraternity and sorority on or near the campus. The sampling plan was developed such that every residential location was visited at least six times: once both before and after midnight on (1) a week night (Sunday through Wednesday), (2) a Thursday night and (3) a weekend night (Friday and Saturday). Most locations were visited several times within each of these time blocks. On each night that data were collected, three interview teams covered separate routes. Respondents were sampled near entrances to student residences.

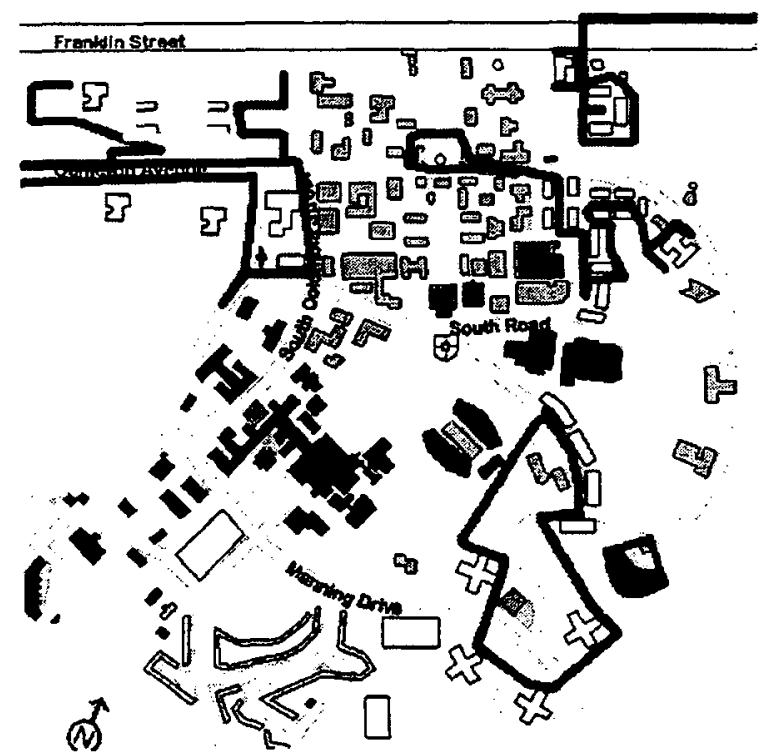

Figure 2.1 Diagram of on-camplis routes followed by data collection teams. 
To avoid attracting too much attention, interview teams moved continuously between locations, typically collecting data at a single location for no more than 10 minutes on a single visit. As teams approached residences they randomly sampled individuals or groups who were either approaching the residence or who were standing in front of the residence and apparently belonged there (i.e., they were not merely passing by).

Figure 2.1 shows a diagram of the on-campus routes the interview teams covered. Starting points on each route were randomly selected to ensure that no particular location was more likely than others to be used for interviewing. Approximately half of the undergraduate student body lives on campus.

In order to obtain information about those who live in private residences we also conducted interviews at five large apartment complexes that, according to university records, housed a large concentration of university students. At these locations, the interview procedure resembled that typically used in roadside surveys (Foss, Beirness \& Sprattler, 1993).

\section{Interview procedure}

Data were collected on 18 nights between October 2, 1997 and November 14, 1997, between $10 \mathrm{pm}$ and $3 \mathrm{am}$, including all nights of the week. Three separate interview teams (consisting of a supervisor and 3 interviewers) worked on each night that data were collected. Groups of individuals were randomly selected (using a die) then approached by a single member of the interview team and asked if they would participate. Once consent was obtained, all members of two- or three-person groups were interviewed. For larger groups, the die was used to randomly sample three individuals for the interview. Interviewers and their respondents stepped away from any other individuals in the area to preserve confidentiality of the interviews and to avoid contamination of responses due to the presence of friends or acquaintances.

The interview took approximately 4 minutes and requested information about students' activities during the night, drinking (where, when, what, how much), perceptions about alcohol use among students, mode of transportation and ways used to avoid drinking-driving. Those who reported drinking during the evening were asked whether they felt any effects of the alcohol and to estimate their BAC. To obtain the BAC estimate, we used a technique developed for experimental research and adapted to field interviews with drinkers (Beirness et al., 1995). Respondents were shown an analog scale representing BAC values from .00 to .24 , with .08 marked as the illegal limit for drivers. ${ }^{1}$ They were asked to indicate where on that scale they thought their own BAC was at the time. Upon completing the interview, respondents were asked to provide a breath sample, which was taken and analyzed using a portable breath test device, the Lion S-D2 IntoxilyzerTM. Persons who declined to be interviewed were asked if they would simply provide a breath sample. Interviewers showed all respondents their BAC readings and provided a brief explanation of the risks associated with that level BAC.

\footnotetext{
${ }^{1} \mathrm{BAC}$ values in this report refer to percent alcohol by volume. Hence, .08 indicates a concentration of $.08 \%$ alcohol in the respondents' blood. This is sometimes reported as, and is equivalent to, 80 milligrams per deciliter ( 80 $\mathrm{mg} / \mathrm{dL})$.
} 
At off-campus residences, vehicles entering the parking lot for a complex were motioned to stop. Interviewers introduced themselves and asked if anyone in the vehicle was a UNC-CH student. If a student was present, that person(s) as well as the driver (if a non-student) was interviewed as described above while they remained in their vehicles.

Dealing with students thought to be at risk due to excessive alcohol consumption

HSRC researchers have conducted studies in which more than 40,000 individuals throughout North America have been interviewed and breath-tested during the past decade. Based on this experience, we did not anticipate more than an occasional minor problem with students who may have had so much to drink that they were at risk for alcohol poisoning or other medical consequences. Nonetheless, as is always the case, extensive precautions were taken for dealing with any person who was a risk to him/herself or others by virtue of risky alcohol consumption. For the first few nights of data collection, a substance abuse counselor from the Student Health Service accompanied the research teams to assist any student who might need help due to alcohol impairment (after no problems were detected during the first few nights, the procedure was modified so that a counselor was always on call at the Student Health Service while data were being collected). All research team supervisors carried mobile telephones so they were able to contact other teams, the project supervisor, the university student health service, the local emergency department and the campus or local police at any time.

Interviewers were trained to attend to several sources of information that would indicate there was reason for concern about a student's welfare, and especially whether there was any possibility of alcohol poisoning. ${ }^{2}$ Any time an interviewer had a concern, the team supervisor was called over to speak to the student. The supervisor then assessed the situation and decided what, if any, protective action should be taken. Three types of information were available to interviewers that could indicate a student had consumed enough alcohol, or had done so in such a manner, that he or she might experience a serious medical problem. The main sources of information were the student's behavior (e.g., difficulty walking, standing or talking; signs of feeling sick; disorientation or confusion) and statements made during the interview (e.g., mentioning very recent consumption of a large amount of alcohol that might not yet be reflected in either their behavior or BAC measurement). The final source of information was the measured BAC. Because the effects of alcohol vary substantially across individuals, we were reluctant to identify a BAC level that was itself a cause for concern. Rather, the BAC measurement was considered in conjunction with the other two sources For example, a moderate BAC measurement would not be cause for concern, but in conjunction with a statement about having just consumed several shots would suggest a potential problem as the recently-consumed alcohol entered the bloodstream. In such a case, the team supervisor would be notified and could take a second BAC measurement to determine whether the student's BAC was rising rapidly.

2 Since students were interviewed when returning home, rather than at a location away from home, there was little concern about the risk to them of driving after drinking. Nonetheless, those persons who registered a BAC above .05 were explicitly told that they should not even consider driving should they decide to go back out because it was both dangerous and illegal to do so. 


\section{Questionnaire}

It is necessary to keep interview times to a minimum when collecting data outdoors late at night. Accordingly, we asked a relatively small number of questions in the interview. ${ }^{3}$ To guide selection of questions from among the large number that might have been asked, we settled on the principle that, to be included, a question should either (1) ask for information that can meaningfully be provided only when asked in situ, that is, at a particular location or time for which it is appropriate (e.g., "How do you feel right now," to assess subjective experience of alcohol impairment) or (2) be uniquely valuable in conjunction with a BAC measurement (e.g., "How many drinks have you had tonight?" or "How did you get home tonight?"). In addition to soliciting basic demographic information, a few questions were asked about drinking behavior during the evening, one pertained to drinking during the past two weeks, others dealt with subjective feelings/perceptions, transportation and activities during the evening other than drinking. Interviews typically lasted from 3 to 5 minutes. A copy of the questionnaire is included in Appendix 2.a.

\section{Pre-survey news conference}

Because this was an unusual kind of study for a college campus, we held a news conference prior to beginning data collection to announce the survey. The goal was to ensure that students knew in advance they might encounter interview teams and what the teams were doing. It was important for students to recognize that this was not part of an enforcement effort. Such a belief would have dramatically reduced cooperation. The Director of the Governor's Highway Safety Program spoke briefly to explain why his office was supporting the project. The president of the student body also spoke, giving his strong endorsement of the study. Following these speakers, several members of the project team explained the study, its purpose and demonstrated survey procedures for collecting a breath sample. The story was well covered by most local print and electronic media, including the student daily newspaper which is read by a very large percent of the undergraduate student body.

\section{Concerns and cooperation of university officials}

Although university officials approached this study with some trepidation, they were extremely interested in having an additional, objective, source of information about student drinking. The greatest concern was that the interview team would encounter students who were extremely intoxicated and that the university would experience increased liability should they subsequently injure themselves or someone else. It was made clear to all university officials that research teams doing BAC surveys always take extensive precautions to ensure that anyone whose well-being might be in question as a result of drinking is taken care of (as described above). This is a typical reaction to BAC surveys and is based, at least in part, on the misperception by nearly everyone, that drinking is a great deal more common and extreme than is actually the case. This general misperception probably results, in part, from the tendency for the news media to focus attention on extreme cases.

${ }^{3}$ OMB approval for these interviews was not requested. Instead, to enable us to supplement BAC measurements with interview data, we obtained funding from other sources to conduct brief interviews with respondents. 


\section{Findings}

Of the 2,530 persons contacted, $86 \%{ }^{4}$ cooperated to some degree; $2,023(80 \%)$ completed the interview and provided a breath measurement; $4.3 \%$ declined the interview, but did provide a breath sample, and $2.1 \%$ did the interview but would not provide a breath sample. Among the latter, 7 (13\%) showed evidence of drinking. Among the $14 \%$ who refused to participate from the beginning, 64 (19\%) exhibited evidence of drinking (typically the smell of alcohol). Although this assessment is based on interviewer observation and judgment, it is consistent with the extent of drinking found among those who did provide a breath measurement. As has been found in late night breath measurement surveys of drivers (Beirness, Foss \& Mercer, 1998), the most common reason for declining to participate was being in a hurry, followed by simple lack of interest in being interviewed, that is, not wanting to be bothered, rather than a concern about being discovered to be drinking. Typical reasons given for refusing were the time of night in conjunction with an early morning class or test and being cold (although it was late fall and some nights were quite cold, individuals were often encountered without coats as they rushed from a car to their residence).

Although sampled persons were interviewed regardless of their student status, results presented here represent only those 1,841 individuals explicitly identified as students enrolled at UNC-CH. ${ }^{5}$ A breath alcohol measurement was obtained for $1,786(97 \%)$ of these individuals. It should be noted that we are unable to determine student status for persons who either refused the entire interview, or who provided only a breath sample. Alcohol use among the latter group, as indicated by measured BAC, was virtually identical to that of known students for whom results are presented here.

\section{Sample characteristics and representativeness}

To determine whether the sample of students we interviewed are representative of the general student population, we compared demographic characteristics of respondents with university records. Table 2.1 shows characteristics of the sample and of the UNC-CH student body as a whole (during the fall semester of 1997).

It is clear that the sample composition differs somewhat from the university as a whole. The overrepresentation of younger students was to be expected since data collection was concentrated on and

4 Throughout this report, percentage values are normally rounded to whole numbers. However, in cases where rounding would create a substantial distortion (i.e., values less than $10 \%$ ), one place beyond the decimal point is typically retained.

5 It is not possible to determine the cooperation rate only for students since we did not learn whether individuals were students unless they agreed to the interview. 


\section{Table 2.1}

Demographic characteristics of survey sample compared with student population at UNC-CH, Fall 1997

\begin{tabular}{lcc}
\hline Characteristic & BAC Survey & All Students \\
\hline \hline Freshman & $34 \%$ & $23 \%$ \\
Sophomore & 26 & 21 \\
Junior & 21 & 26 \\
Senior & 16 & 27 \\
Other & 4 & 3 \\
\hline Male & 49 & 40 \\
Female & 51 & 60 \\
\hline White & 84 & 81 \\
Black & 10 & 11 \\
Other & 6 & 8 \\
\hline Greek* & 25 & 18 \\
Non-Greek & 75 & 82 \\
\hline \hline
\end{tabular}

* Member of social fraternity or sorority

near campus, where younger students are more likely to live. The overrepresentation of males probably reflects the fact that data were collected late at night when males are probably more likely than females to be outside. The overrepresentation of members of Greek organizations probably results from the fact that they are more likely to live in smaller residence units (fraternity/sorority houses average about 40 persons, whereas residence halls average several hundred occupants), increasing their likelihood of selection when a team was at their location.

In sum, the demographic characteristics of the sample differs somewhat from that of the UNC-CH student body in that it is somewhat younger and contains more males. The greater concern is whether drinkers were properly represented in the sample. The high response rate, which far exceeds that of most telephone or questionnaire surveys, provides some assurance that the sample is a good representation of the population of interest. There is some question about whether sampling only persons who were outdoors may have resulted in our missing persons who remained inside for the entire evening, especially if those individuals are more likely to be drinkers. Information available from a self-report mailed questionnaire survey administered by the university at the same time of the BAC survey allows us to 
address this issue. A typical question to assess student drinking is "About how many times in the past two weeks have you had five or more drinks in a row?" In that self-report survey of students at UNC-CH, $38 \%$ had done this at least once; in the BAC survey which asked the same question, $49 \%$ indicated that they had consumed five or more drinks in a row during the past two weeks. Hence, if anything, the BAC survey may have an overrepresentation of drinkers. That is not necessarily the case, however, as the response rate to the mailed questionnaire was only $50 \%$, raising the equally plausible explanation that drinkers were less likely to take the time to respond to that questionnaire.

\section{Weighting}

To provide an overall estimate of alcohol use for the campus, data were weighted to equalize the contribution of each day of the week, since approximately twice as much time was spent interviewing on Thursday, Friday and Saturday nights as on other nights of the week.

Table 2.2 shows the full BAC distribution for the three times of the week studied, in addition to the overall distribution weighted to adjust for oversampling of weekend and Thursday nights.

\section{Table 2.2}

Blood alcohol concentration of students by time of week (percent)

\begin{tabular}{crccc}
\hline BAC & Week night & Thursday night & Weekend night & All nights* \\
\hline .00 & 86.0 & 67.0 & 64.0 & 77.0 \\
$.01-.049$ & 3.9 & 8.8 & 14.0 & 7.4 \\
$.05-.079$ & 3.3 & 7.9 & 6.2 & 4.7 \\
$.08-.099$ & 1.0 & 3.8 & 4.1 & 2.3 \\
$.10-.149$ & 5.7 & 14.0 & 9.2 & 6.9 \\
$.15-.199$ & .5 & 1.4 & 1.6 & .9 \\
.20 or higher & .7 & .8 & 1.1 & .8 \\
\hline $\mathrm{n}=$ & 615 & 366 & 805 & 1786 \\
\hline \hline
\end{tabular}

* Weighted to adjust for oversampling of Thursday through Saturday nights. 
For simplicity of reporting subsequent analyses, various cut points along the BAC continuum are used to create dichotomous variables. Here we use three points: Any non-zero reading, as an indication of drinking; .08, to represent substantial drinking; and .15 as a measure of heavy drinking. The selection of cut points is often fairly arbitrary. Zero vs. a positive reading is clearly not arbitrary. The .08 point was chosen based on the fact that this is the illegal limit for operating a motor vehicle in North Carolina. As such it reflects a legally meaningful point, but beyond that it is a somewhat arbitrary dividing line. To designate a BAC level to indicate heavy drinking, we queried several survey researchers with experience measuring BAC values in non-clinical populations. They were asked what BAC level a "binge" drinker would probably exhibit and they were nearly unanimous in suggesting .15.

\section{Any drinking}

Overall, $26 \%$ of students reported drinking and $23 \%$ registered a non-zero BAC. These were mostly, but not always, the same individuals. Among those who reported drinking during the evening, $12 \%$ registered a .00 BAC and another $11 \%$ were below .02 . Conversely, $1.7 \%$ reported not drinking but registered a positive BAC value; most of these were below .05. As Table 2.2 shows, drinking on Thursdays was similar to that on weekends. On week nights, drinking was less common, but among those who did drink, BACs reached similarly high levels. For example, among those 534 respondents who reported drinking during the evening, $41 \%$ had a BAC of .08 or higher, and this did not differ by day of week $(p>.60)$.

\section{Heavy drinking}

Heavy drinking among college students has typically been measured as self-reported consumption of five or more drinks on an occasion at least once during the past two weeks. Using this criterion, $49 \%$ of respondents were heavy drinkers; $24 \%$ qualified as frequent heavy drinkers (five or more drinks on three or more occasions in the past 14 days). On the evening of the interview, however, only $11 \%$ qualified as heavy drinkers based on self-reported consumption of five or more drinks. Among those individuals who qualified as heavy drinkers on the evening they were interviewed the mean BAC was .10.

In contrast to the self-report data, measured BACs present a somewhat different picture. Although the self-reported heavy drinking rate in this sample is $49 \%$, there is no day of the week when more than $36 \%$ of students had BAC above .00 . The proportion with a BAC above .08 never exceeded $16 \%$ and the proportion with a really high $\mathrm{BAC}(.15)$ was never more than $3 \%$.

Of particular interest is the relationship of BAC to reports of heavy drinking. Examining the BACs of those persons who would be classified as heavy or risky drinkers by the standard measure of that concept among college students ( 5 in a row for males, 4 for females in the past two weeks), $61 \%$ had a BAC of .00 on the night they were interviewed. Nineteen percent were above .08 , but only $3.4 \%$ had a very high BAC $(\geq .15)$.

Self reports of drinking on the night of interview were more closely associated with BAC. Table 2.3 shows the BAC distribution for those who reported having five or more drinks for males or four or more 
for females on the night they were in?

Clearly a substantial number of these individuals had dangerously high BACs. On the other and, there is also a substantial number with relatively low BACs. It is worth noting that $37 \%$ of those who qualified as a "binge" drinker on the night they were interviewed had a BAC below the per se illegal BAC limit (.08) for drivers in North Carolina. ${ }^{6}$

\section{Table 2.3}

\section{BAC distribution for "binge" drinkers*}

\begin{tabular}{lc}
\hline BAC range & Percent \\
\hline$\leq .049$ & 15 \\
$.05-.079$ & 22 \\
$.08-.099$ & 15 \\
$.10-.149$ & 37 \\
$\geq .15$ & 11 \\
\hline $\mathrm{n}=270$ & 100 \\
\hline$*$ Males who reported having five or more drinks \\
during the evening, females who reported four or more.
\end{tabular}

\section{Drinking among demographic subgroups}

Drinking was more common among persons above the legal drinking age ( $29 \%$ vs. $22 \%, \mathrm{p}<.01)$, but BACs above .08 were equally common for persons below and above the legal drinking age (11\% in both cases). Males were more likely than females to have positive BACs ( $28 \%$ vs $20 \%, \mathrm{p}<.01)$, as well as BACs above .08 ( $13 \%$ vs $8 \%, \mathrm{p}<.01$ ). White students $(27 \%)$ were more likely than black students $(7 \%)$, as well as those of other races $(11 \%)$, to be drinking and to have BACs above .08 (12\% white, $3 \%$ black, $4 \%$ other; $\mathrm{p}<.01$ ). Members of Greek organizations were more likely to have positive BACs ( $44 \%$ vs. $17 \%, \mathrm{p}<.01)$ and BACs over $.08(23 \%$ vs. $7 \%, \mathrm{p}<.01)$ than those who did not belong to Greek organizations.

6 Although the legal drinking age was 21 at the time, the BAC limit for drivers ages 18-20 remained the same as for older drivers (.08). Shortly after the completion of this survey, North Carolina's Zero Tolerance limit (.00) for underage drinkers was extended to include persons between 18 and 20 . 
Time of night

Obtaining data in situ

allowed us to examine how

drinking and, more

importantly, BAC levels

change as a function of

time of night. Even on

weekends, drinking is

typically a nighttime

activity among students.

The average time of first

drink on every day was

approximately 10 p.m.

except Saturday when it

was $9: 30$ p.m. Figure 2.2

shows the proportion of

respondents with a $\mathrm{BAC}$

above $.00, .08$ and .15 by

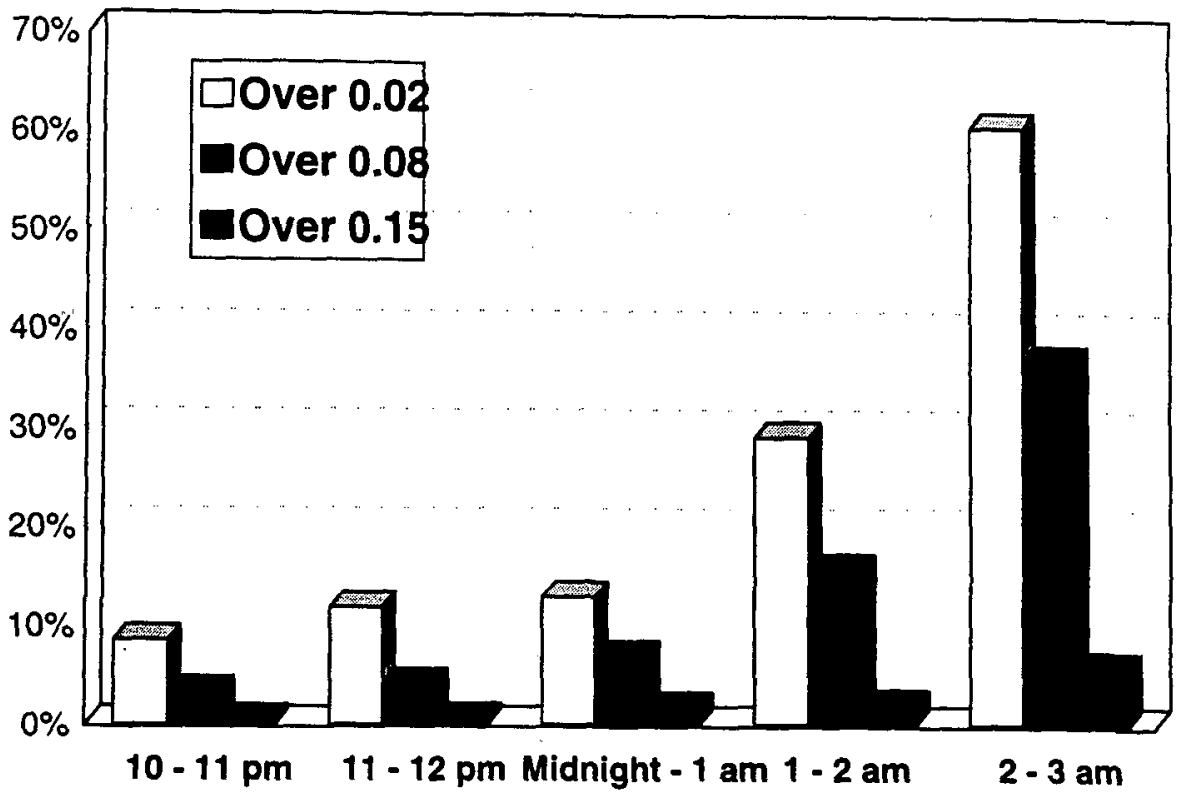

Figure 2.2 Proportion of students with BACs above three thresholds by time of night.

time of interview.

\section{Football weekends}

In our efforts to pinpoint the nature and location of problems with student alcohol use, one question was whether celebrations associated with football games might be a particularly important intervention point. On most college campuses, it is believed that sporting events, especially football, and drinking go hand-in-hand. To determine whether drinking, or excessive drinking, is more common in conjunction with home football games, we compared BAC information for the two Saturdays when there was a home football game with Saturdays when there was no game. Table 2.4 shows the proportion of students whose BAC was at or above each of three levels $(.00, .08$ and .15$)$ on typical Saturday nights and the dates of Homecoming and the "Big Game."?

Although there are clear differences, it is difficult to detect any meaningful pattern. Drinking was substantially more common on the Saturday evening of homecoming, but on the night of what was called the "Game of the Century" locally, drinking was no different from other Saturdays. There are several differences between the two Saturdays that may be related to drinking. The homecoming game was an afternoon game, and the home team won. The Big Game was a night game, and the home team lost. Unfortunately, with only one of each, it is not possible to detect any pattern associated with game days, day vs. night games, or wins vs. losses.

7 This game pitted the number one rated team in the country against the undefeated home team, which was rated \#3 at the time. 


\section{Table 2.4}

Proportion of respondents with $\mathrm{BAC}$ above three thresholds on football Saturdays vs. other Saturdays.

\begin{tabular}{lccc}
\hline Date & BAC $>.00$ & BAC $\geq .08$ & BAC $\geq . \mathbf{1 5}$ \\
\hline \hline $\begin{array}{l}\text { Typical Saturday } \\
(\mathrm{n}=322)\end{array}$ & $30 \%$ & $13 \%$ & $2.8 \%$ \\
$\begin{array}{l}\text { Homecoming Saturday } \\
(\mathrm{n}=138)\end{array}$ & $51 \%$ & $25 \%$ & $3.6 \%$ \\
$\begin{array}{l}\text { Big Game Saturday } \\
(\mathrm{n}=81)\end{array}$ & $26 \%$ & $10 \%$ & $3.7 \%$ \\
& & & \\
\hline
\end{tabular}

\section{Drinking location}

The large majority of drinkers (63\%) reported drinking in a single location on the night they were interviewed. Another 30\% reported drinking in two locations. Persons who reported drinking in two or more locations were more than twice as likely as those who drank in one location to have a BAC above $.08(57 \%$ vs. $33 \%, \mathrm{p}<.01)$ and more than five times as likely ( $15 \%$ vs. $3 \% ; \mathrm{p}<.01)$ as those who drank in one location to have a very high $\mathrm{BAC}(\geq .15)$. It is not possible to determine whether this was due specifically to the number of locations or simply the fact that those who drank in more than one location spent a longer time drinking.

The most common drinking locations were bars and parties. The majority of parties (about 80\%) were affiliated with a campus fraternity. Although the amount of drinking did not differ for those over and under the legal drinking age, the location of drinking did differ, in predictable fashion. Underage respondents were much less likely to drink in a bar or restaurant, although substantial percentages still did so. Fifty-four percent of respondents age 21 or older had their last drink in a bar, compared to $12 \%$ of those under $21(p<.01)$.

\section{Transportation mode: drivers, passengers, pedestrians}

Of particular interest in this study was the question of whether, and if so how, students' BACs varied by the mode of transportation they used to come home. Table 2.5 shows the proportion of individuals with positive (non-zero) BACs and those above .08 for each of four most common modes of transportation.

It appears that UNC-CH students are doing a good job of ensuring that persons who have had too much to drink are not driving. Persons with any alcohol, as well as those with high BACs are much more likely to transport themselves home as a passenger (in a car or bus) or by walking than they are to drive. It is noteworthy that the proportion of drivers with a BAC above .08 is nearly identical to the proportion of 
the general nighttime driving population in North Carolina (Foss et al., 1995) found to be that high in a 1994 statewide roadside survey ( $2.4 \% \mathrm{NC}$ vs. $2.6 \% \mathrm{UNC}-\mathrm{CH})$.

Table 2.5

Percent of respondents with BAC above .00 and .08 by mode of arrival

\begin{tabular}{lcc}
\hline Arrival mode & BAC $>.00$ & BAC $\geq .08$ \\
\hline Car driver $(\mathrm{n}=302)$ & 12 & 2.6 \\
Car passenger $(\mathrm{n}=189)$ & 26 & 9.0 \\
Pedestrian $(\mathrm{n}=880)$ & 24 & 13.0 \\
Bus* $(\mathrm{n}=153)$ & 18 & 7.2 \\
\hline
\end{tabular}

* Includes Campus Shuttle

\section{Perceptions of drinking norms}

Nearly two-thirds of students (63\%) believe they drink less than the typical UNC student, whereas only $10 \%$ believe they drink more. This tendency to think others drink more was also evident when individuals were questioned about their drinking in comparison to those they were with at the time they were interviewed. When asked whether they thought the BAC of others in the group they were with was higher or lower than their own, $38 \%$ thought others were higher, $42 \%$ thought they were about the same and only $20 \%$ thought the others had a lower BAC.

Fifty-seven percent of those persons who reported having 5 or more drinks at least three times within the past two weeks (sometimes called "frequent binge drinkers") believed they drink the same amount as others on campus; $10 \%$ think they drink less! In contrast, among those most representative of student drinking (i.e.,

It is clear that heavy drinkers believe they are the norm on campus, whereas lighter, less frequent drinkers, despite being in the distinct majority, believe they are atypical. those who have not had more than five drinks on three or more occasions in the past two weeks, reflecting $76 \%$ of the sample we interviewed), $80 \%$ believe they drink less than the typical UNC student. It is clear that heavy drinkers believe they are the norm on campus, whereas lighter, less frequent drinkers, despite being in the distinct majority, believe they are atypical.

There is a tendency for first year students to have an even more exaggerated perception of being "out of sync" with drinking on campus. When comparing themselves to other students on campus, first year students are somewhat more likely than older students to say that they drink less than the typical UNC-CH 
student ( $66 \%$ vs $62 \%, \mathrm{p}<.05)$. Even more striking is that those freshmen who had consumed enough alcohol on the night they were interviewed to have a BAC greater than .08 were less realistic than older students (with the same high BAC) in assessing how their drinking compares to that of the typical UNC$\mathrm{CH}$ student. Whereas $35 \%$ of freshmen with a $\mathrm{BAC}$ above .08 thought they drank less than the typical UNC-CH student, only $20 \%$ of older students thought they drank less than the typical student $(\mathrm{p}<.05)$. Conducting this analysis using other indicators of drinking (positive BAC, self-report of heavy drinking) produced similar evidence that freshmen are even more out of line in their perceptions about student drinking than students who have been on campus for a year or more.

\section{Implications}

- There is a clear need to address the substantial misperceptions of students about how typical drinking and excessive drinking are among UNC-CH students.

- There is a special need to target freshmen, who appear to have the least accurate perception, to reduce the strong implicit pressure to drink that results from their overestimation of the prevalence of alcohol use among students.

- Efforts are needed to increase responsible beverage service in bars and restaurants. This might include increased efforts to check age of patrons before serving alcohol. Recognizing that there are many difficulties in doing this, at a minimum establishments that serve alcohol need to be more vigilant about preventing patrons from consuming too much, regardless of whether they are of legal drinking age. A comprehensive campus-community coalition needs to address such things, as has been done in other university communities (Albany, New York; Bellingham, Washington; Lincoln, Nebraska).

- Efforts are also needed to address another source of alcohol for a substantial number of students: private parties (usually hosted by a fraternity). Ideally this would come from Greek organizations themselves rather than being imposed on them.

The latter two of these are beyond the scope of the present project. However, university officials are working on both through other avenues and have embraced the program described in this report as an integral part of the overall program to reduce problems associated with students use of alcohol.

The focus of our program was the first two issues listed above: pressures on students to drink resulting from overestimates of the extent of student drinking and the particularly large problem with misperceptions among first year students. Because incoming freshmen are just beginning a new phase in their lives during their first several weeks on campus, university officials are particularly concerned that they begin their college careers on the right foot. In view of the array of serious problems that can result in students' lives if they become involved with excessive drinking, we decided to put a particular emphasis on enlightening freshmen about the realities of student drinking discovered in the BAC survey. 


\section{Program Development}

\section{A Social Norms approach}

According to social learning theory (Bandura, 1977), for which there is extensive empirical support, individuals' behaviors are strongly influenced by what they perceive to be normative in the culture of the groups to which they belong. During the 1980 s, researchers began to recognize that there are substantial misperceptions about the amount of drinking that occurs among college students (Perkins \& Berkowitz, 1986). This led to a realization that it might be possible to reduce actual drinking simply by reducing these misperceptions, thereby lowering a strong perceived pressure to drink. Some sophisticated social marketing programs have been developed to help college students understand that, despite all the reports they have heard about student alcohol use, the norm for alcohol use among college students is actually moderation rather than excess (Haines, 1996; Johannessen et al., 1999).

\section{Exaggerating the problem can exacerbate it}

A logical deduction from social learning theory is that approaching a problem by exaggerating its magnitude may backfire. If, in the process of advocating for the need to address a risky behavior, we begin to give the impression that it is more common than is actually the case, we may well contribute to misperceptions about normative behavior. There is a sense among many university health professionals that the heavy media focus on student drinking may have begun to have this effect. Headlines in the national media about student deaths from alcohol poisoning (a tragic, but extremely rare, event) are routinely juxtaposed with findings from questionnaire surveys indicating that a substantial proportion of students report having had four or five drinks on a single occasion. Unfortunately, the phenomenon reported in surveys (usually labeled in the media as "binge drinking") is not synonymous with the kind of behavior that results in alcohol poisoning. What is missed in typical reports and discussions of student alcohol use is that the excessive behaviors that make for good on-air footage and flashy headlines are extremely rare as a proportion of all student behavior and, indeed, of all student drinking behavior.

\section{An inclusive approach}

The social norms approach to reducing excessive drinking focuses on helping individuals (in this case college students) to recognize the reality of student drinking. It is not (directly) prescriptive, but rather is informative. In order to be effective, this approach cannot single out specific groups. It must focus on the entire student body. Because the actual amount of drinking and, therefore, normative drinking are less than believed, simply persuading all students to understand the misperception should reduce pressures to drink for those who are light or non-drinkers. The simple facts about student drinking provide social support for those who don't drink or who drink occasionally and lightly, since they are in the clear 
majority. At the same time, this information should help to remove the perceived social support for the behavior of those who drink frequently and heavily, since they are a small minority.

Because of the way this approach works to reduce drinking, neither individuals nor particular groups are singled out directly. Thus, although males were found to drink more than females, they are not treated separately from females on campus. Similarly, although members of Greek social organizations were more likely to drink than non-Greeks, there was no need to focus on them as different. Indirectly, all groups (and individuals) are targeted by virtue of the message. If their drinking behavior is "typical," then the message about what is normative among students on the campus helps to support that behavior. On the other hand, if their drinking behavior is heavier than typical, then the message tends to single them out as just that: atypical. In so doing, it brings implicit social pressure to bear on them to bring their behavior more in line with that which is normative on the campus. Hence, people are implicitly singled out, but the focus is low-key and is based on their behavior rather than their membership in any group or social category.

\section{Development of the UNC-CH " 2 out of 3" program}

In view of evidence about the usefulness of the social norms approach, we developed such a program for the UNC-CH campus. Numerous conversations with the developers of two of the best known and most carefully evaluated programs (at Northern Illinois University [Haines, 1996] and the University of Arizona [Johannessen et al., 1999]) helped guide development of the UNC-CH program. The UNC-CH program is distinctive in that data on student drinking norms were drawn from a much larger survey than those at Northern Illinois and the University of Arizona (nearly 2,000 vs. several hundred students) and includes objective data on alcohol use in addition to self-reports of drinking. It also draws heavily on successful elements of programs developed elsewhere.

A central concept of a norms program is to avoid directly telling students what they 'should' be doing. Rather, by highlighting and getting students to accurately perceive the true norm, the program relies on their understanding of the norm itself to tell students what they "should" be doing (in this case, moderate or no drinking). Extensive "market-testing" (see below) was done with students as we refined the basic message to ensure that students understood the message to mean what was intended: that drinking among UNC-CH students is not nearly so prevalent as most everyone (including students) seemed to think. As a result, individuals need not feel a pressure to drink.

The most telling single fact that emerged from the BAC survey data is that, on what are considered to be the prime "party nights" (Thursday, Friday and Saturday), fully two-thirds of all students returning home late at night had a zero BAC. 
Developing/refining the basic message

We had a two-fold objective for the message:

create awareness of the alcohol fact among students; and

$\square$ present the fact in a credible manner.

This required working closely with students in the development of potential messages, the refinement of messages and the selection of support information. Six rounds of testing the general concept, the content, the specific wording and the physical layout led finally to the primary message:

\section{"Whether it's Thursday, Friday or Saturday Night, 2 out of 3 UNC Students Return Home with a .00 Blood Alcohol Concentration"}

and the secondary message:

\section{"Most of those who drink have four or less"}

Students were asked to react to " 2 out of 3 UNC students return home with a .00 BAC" and "most of those who drink have four or less" as primary messages. Feedback indicated that the "four or less" message meant differing things to students, with some thinking that four represented a low number of drinks and others thinking it was a lot. The $.00 \mathrm{BAC}$ message was viewed as a stronger, clearer message. However, special care was needed to ensure that the fact was presented in a believable manner since it was such a departure from the common beliefs about drinking among students.

As a result of student feedback, the ".00 BAC" fact became the primary message. The "four or less" fact was included as a secondary message to dispel the notion that the other one third were 'drunk.'

This feedback process also provided insight into how individuals might discount the message. For example, some individuals mentioned that students probably lied about their drinking or that we must have collected data at the wrong times or places to reach the drinkers. To deal with this potential scepticism, each message was accompanied with the additional reminder that this was not mere self-report data, but actual BAC data obtained from a breath sample: "It's not what they say, it's what they blow." In addition, following the recommendation of Haines (1996), the scientific underpinning for this information was always cited:

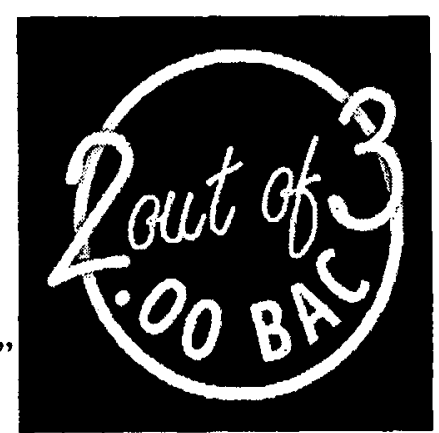

Figure 3.1 Program logo.

"Based on Fall 1997 breathalyzer data collected between 10 p.m. and 3 a.m., as students returned home to fraternities, sororities, residence halls, and off-campus apartments"

A logo was developed (see Figure 3.1) to enhance message recognition and unify program elements. The logo was incorporated into all program materials and displayed during news conferences and presentations. 


\section{Program structure}

The program had four main components:

$\square$ New student alcohol awareness presentation

- Poster incentive campaign

口 Sticker incentive campaign

$\square$ Media plan

\section{New Student Alcohol Awareness Presentation}

The objective of this component was to present the alcohol fact to all new students at UNC and to make them aware that knowing this fact would enable them to win prizes during the fall semester. All incoming students must attend a summer orientation session known as CTOPS (Carolina Testing and Orientation Program Sessions). Many of these students are accompanied by their parents. Through the efforts of the Vice Chancellor for Student Affairs, this project was incorporated in the opening general session (the best attended session and the only one with both parents and students present): This enabled us to present the message to virtually the entire target population. Crafting a presentation that would maximize this opportunity was crucial for future message recognition. We also remembered the caution students had given us to present the message as credibly as possible.

Methods for enhancing credibility included using young HSRC staff (closer in age to the target audience) to present the message, avoiding any appearance of lecturing or telling the students what to do and incorporating comments from students already attending UNC into the presentation. An unpolished video was produced that was a compilation of comments from students on campus. The amateur nature of the video was important because we did not want students to perceive this to be a slick public relations piece. We wanted it to appear as it was - uncut comments from real students. In the video, randomly stopped students were asked what are the party nights at UNC and their responses were recorded (see Figure 3.2). Then the students were told the .00 BAC fact and asked if it was believable.

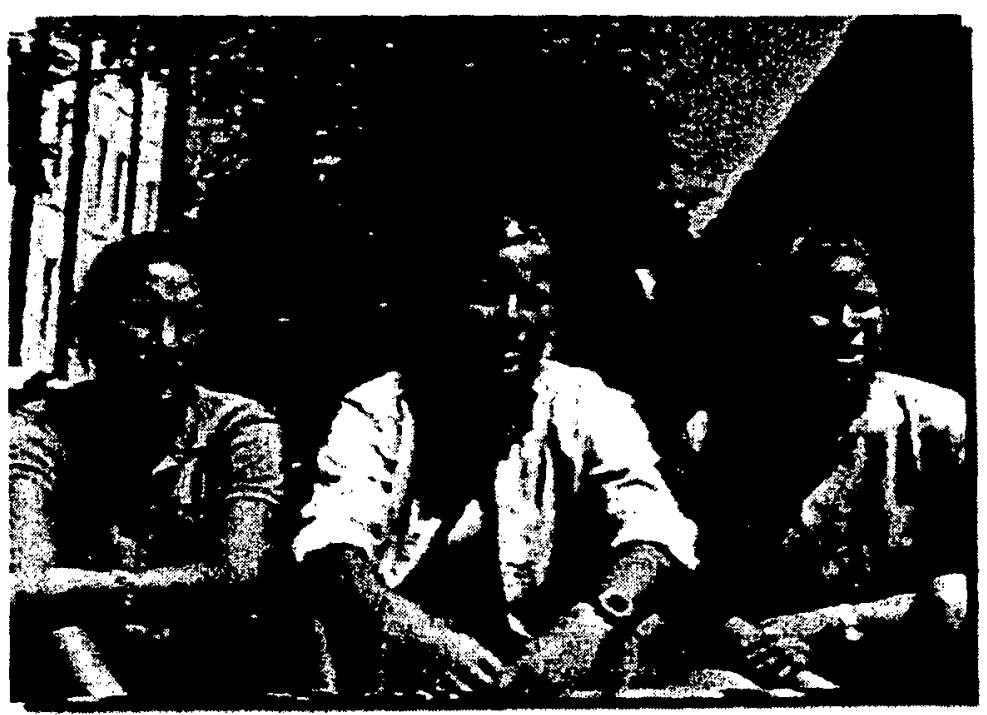

Figure 3.2 Clip from video showing students being intervieweed about drinking at UNC-CH. 
At the opening general session for each CTOP session, a blue, yellow or pink card was given to each parent and student entering the auditorium. Twothirds of the people received blue cards. A majority of the rest received yellow cards. Following her welcoming remarks to new students and their parents, the Vice Chancellor for Student Affairs introduced the two young representatives from HSRC. They explained that they wanted to tell the audience one fact about drinking on the UNC-CH campus. They then showed the first half of the video with students reporting that Thursday,

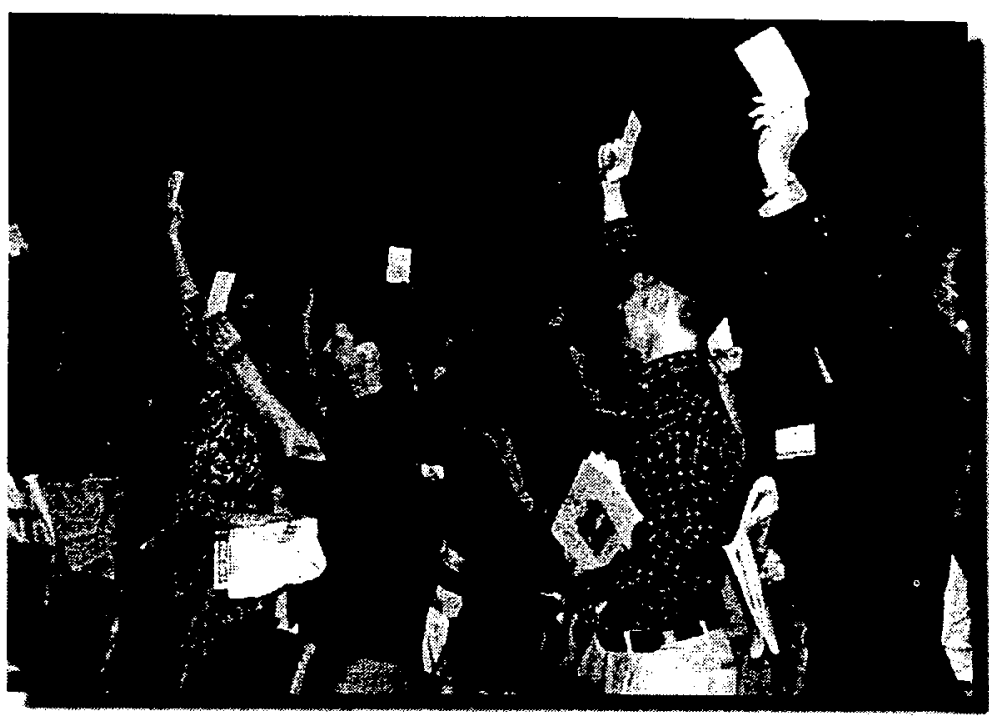

Figure 3.3 Interactive demonstration of the " 2 out of 3" fact at new student orientation session. Friday and Saturday were prime party nights. Then the video was stopped and all the students and parents holding the blue cards were asked to stand (see Figure 3.3). They were asked to look around the auditorium and were told that they represent the proportion of students returning home on Thursday, Friday or Saturday night with a $.00 \mathrm{BAC}$. Those with yellow cards (representing students who consumed four or fewer drinks) or pink cards (representing heavier drinkers) were then asked to stand. Audience reaction clearly indicated surprise about the small proportion representing drinkers. Next, the second part of the video was shown, presenting student reactions to the fact (most of whom indicated that it sounded about right to them; a few also commented that it was encouraging). Finally students were given a card with the " 2 out of 3 " fact and told that knowing it would be worth cash during the upcoming semester (see Figure 3.4). The three ways in which students might win or earn a cash reward (poster, sticker, simply knowing the fact) were briefly explained.

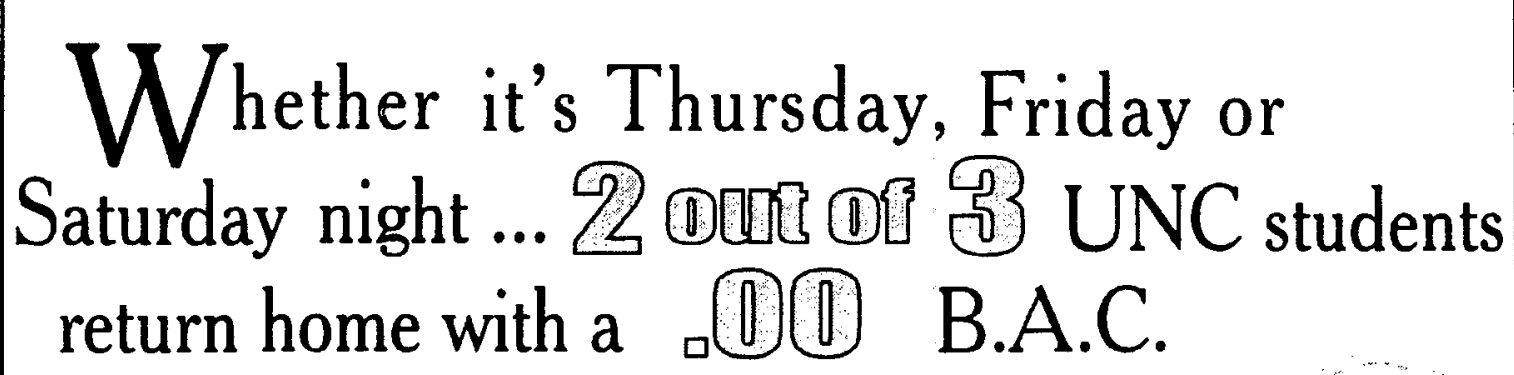

Most of those who drink have 4 or less.

It's not what they say, it's what they blow.

Results based on breathalyzer data collected between 10:00 pm and 3:00 am during Fall 1997 as students returned home to fraternities, sororities, residence halls and apartments.

Figure 3.4 Card handed to students and parents as a reminder of the " 2 out of 3 " fact. 


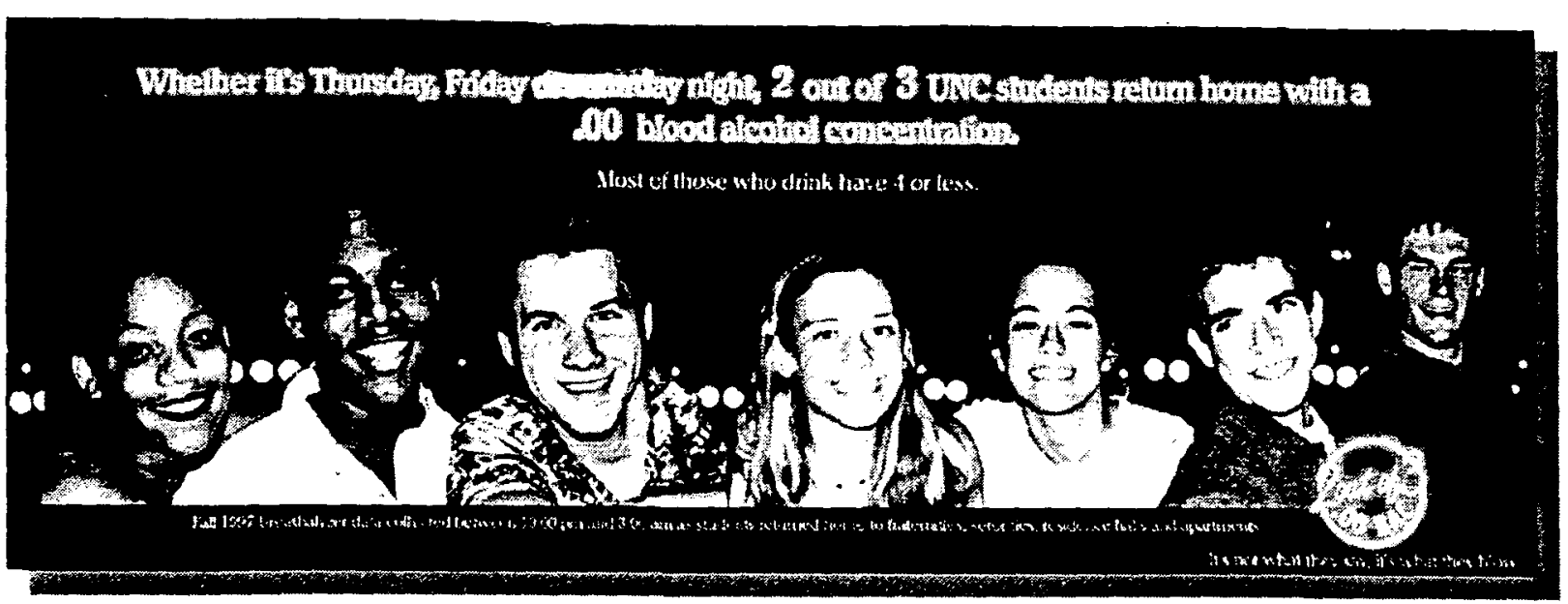

Figure 3.5 Poster displayed in common areas of residence halls.

The full presentation lasted approximately 10 minutes. Ten orientation sessions were held during the summer, beginning in late May. Average attendance at these sessions ranged from approximately 300 to 600 ; in each case the audience was approximately $60 \%$ students and $40 \%$ parents.

\section{Poster Incentive Campaign}

The concept for the poster campaign was to encourage students to keep the message visible - to themselves and others - by offering cash incentives for students randomly "caught" with posters in their rooms. It was important for the posters to be attractive enough for students to be willing to display them and distinctive enough to break through the visual clutter commonly found in student rooms.

The posters were designed in an unusual format (white on black, 8" X 22"). Two posters were developed. One, which emulated those developed at Northern Illinois University and the University of Arizona (featuring students depicted in local scenes), was posted in common areas around campus, including residence halls (see Figure 3.5). The other, which shows the " 2 out of 3" message on the marquee of a local landmark theater along the strip adjacent to campus (see Figure 3.6), was placed on the bed of each incoming freshman student prior to their arrival. These were accompanied by a note explaining that during the upcoming semester, rooms would be visited randomly and if the poster was displayed in a visible location, the occupants of the room would be given $\$ 50$ on the spot. The purpose of offering rewards was to ensure that the simple normative information was widely displayed in locations where students would be likely to see it, as opposed to limiting it only to public areas where a plethora of other materials would compete. Again, we used student feedback to determine the incentive. Not surprisingly, cash had the greatest appeal.

While the poster campaign was limited to first year students, the remaining program elements were designed to reach all students. Given the great mixture on campuses, it is not possible to create a belief among first year students if the rest of the students are unaware, or are in disagreement. Hence, although the initial program focus was on first year students, others needed to be addressed as well. 
The sticker incentive campaign called " $\$ 1$ if you know it, \$5 if you show it," was another means to make knowledge of the fact valuable to students. Stickers with the " 2 out of 3 " logo were given out on campus with the explanation that during fall semester a UNC prize patrol would be randomly stopping students on campus. If students could state the alcohol fact to the prize patrol, they would win a dollar on the spot; if they had the sticker somewhere visibly on them (on their book bag, notebook, etc.) they would win five dollars on the spot. Stickers were distributed at the campus bookstore during the beginning of the semester. They were also handed out by the roving prize patrol to students who were stopped and were unfamiliar with the campaign. In addition, a cut-out version of the sticker was included in the ads in the campus newspaper. The sticker is shown in Figure 3.7. Throughout the fall semester, project team members visited various locations on campus where students congregate, stopping randomly selected individuals and groups to ask if they had the sticker or, if not, whether they knew "the Alcohol Fact." Rewards were distributed accordingly. The sticker campaign was designed to generate word-of-mouth dissemination of the " 2 out of 3 " fact, as well as to increase visibility of the " 2 out of 3 " fact among students.

\section{Support media}

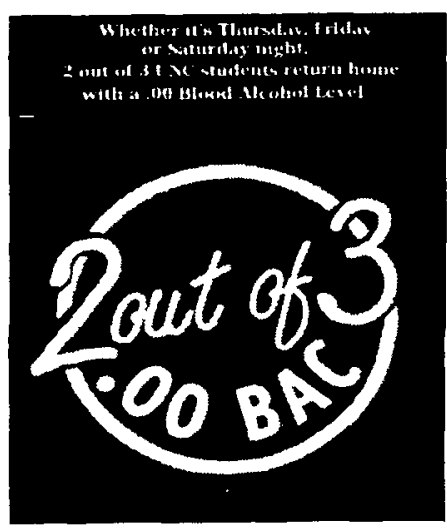

St 4 you those $t$. sis if you show il. All tall semester. the UNC prize patrol will randionly stops stiwents. Karm this a wodiol

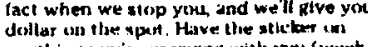

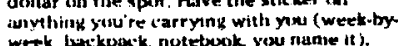
weth. Warke li give you is.

Spomsorect by Student Aliaurs

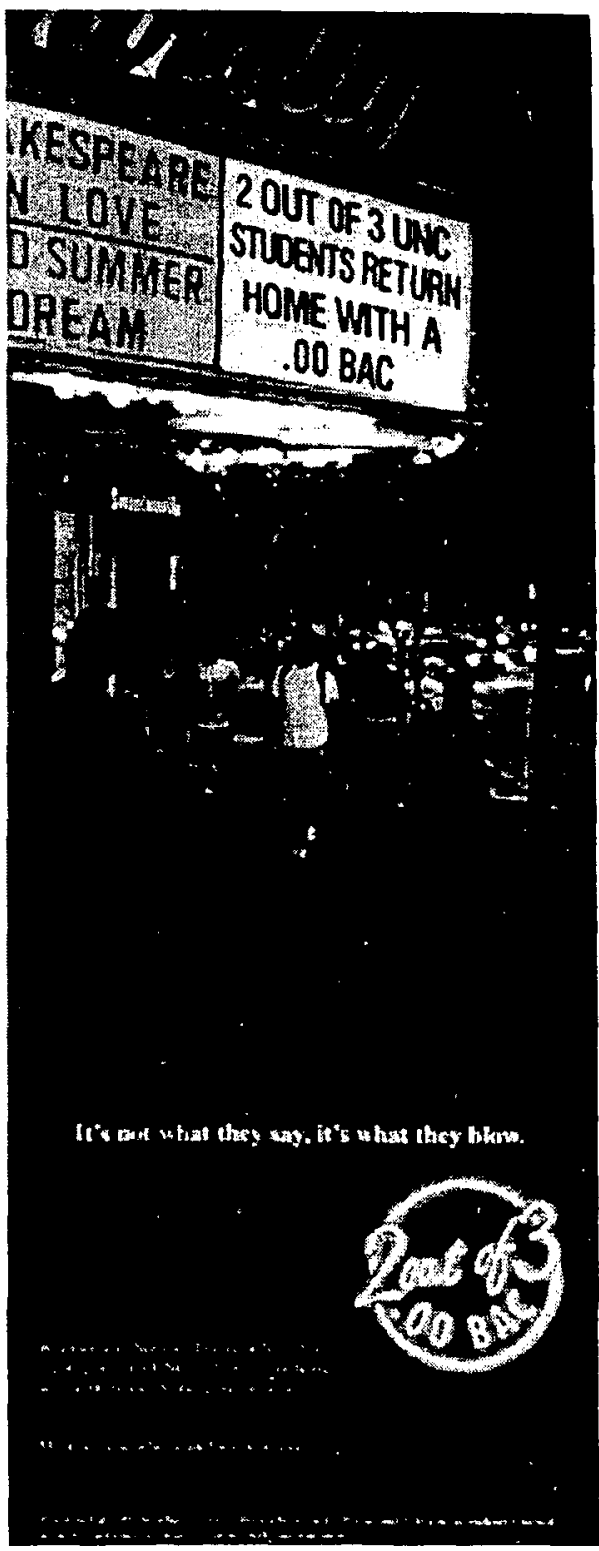

Figure 3.6 Poster distributed to individual student rooms in freshman residence halls. news stories about the results of the data collection, advertisements in the campus newspaper, and the development of a program web site.

News conference. To boost the coverage of the normative message and to reach out to the general public, returning students and their parents, we held a news conference to announce the findings of the survey, focusing on the "2 out of 3" fact (http://www.hsrc.unc.edw/pubinfo/alc_breath.htm). The Vice-Chancellor for Student Affairs, the Student Body President and representatives of the program development team all spoke briefly. This generated widespread coverage in the state and attracted national attention

Figure 3.7 Sticker distributed at various campus locations. 
as well. We believe this coverage was particularly important in that it was a way to disseminate information widely to the general public in North Carolina, the population from which most UNC-CH students are drawn. In addition to coverage in the daily print media, the program was also covered in the Carolina Alumni magazine, reaching an important target audience not often thought to be relevant to campaigns concerning student alcohol use.

Newspaper ads. Large ads were run periodically in the student newspaper to alert students to the fact that the program to reward individuals for carrying the sticker and knowing the "alcohol fact" was under way (see Figures 3.8 through 3.10). Although student newspapers typically have high readership and are a highly cost effective way to reach college students (Johannessen et al., 1999), these ads were used mainly as reinforcers to complement the other channels. However, they were also included as part of the program to help spread the message throughout the entire student body.

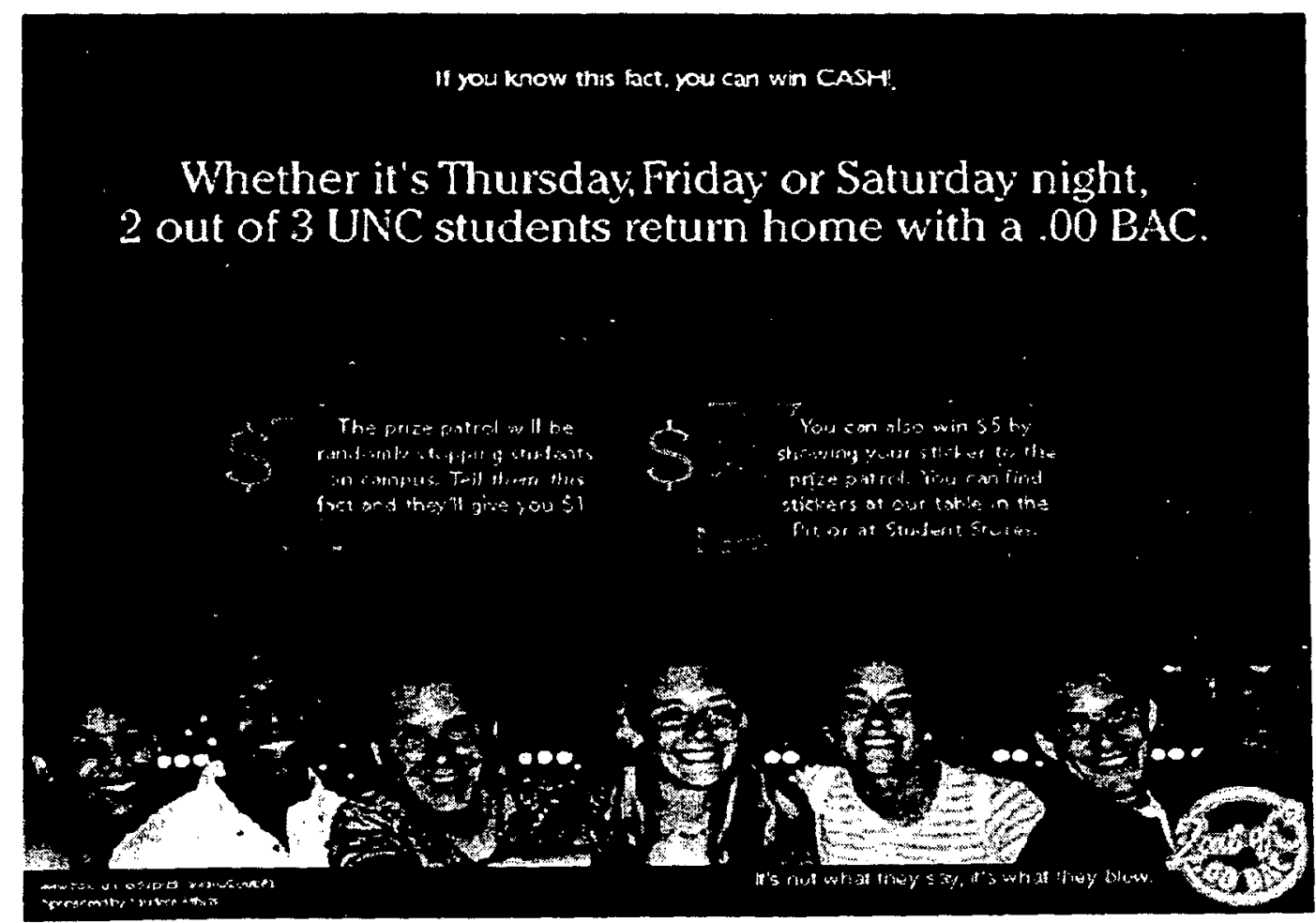

Figure 3.8 First student newspaper advertisement. 


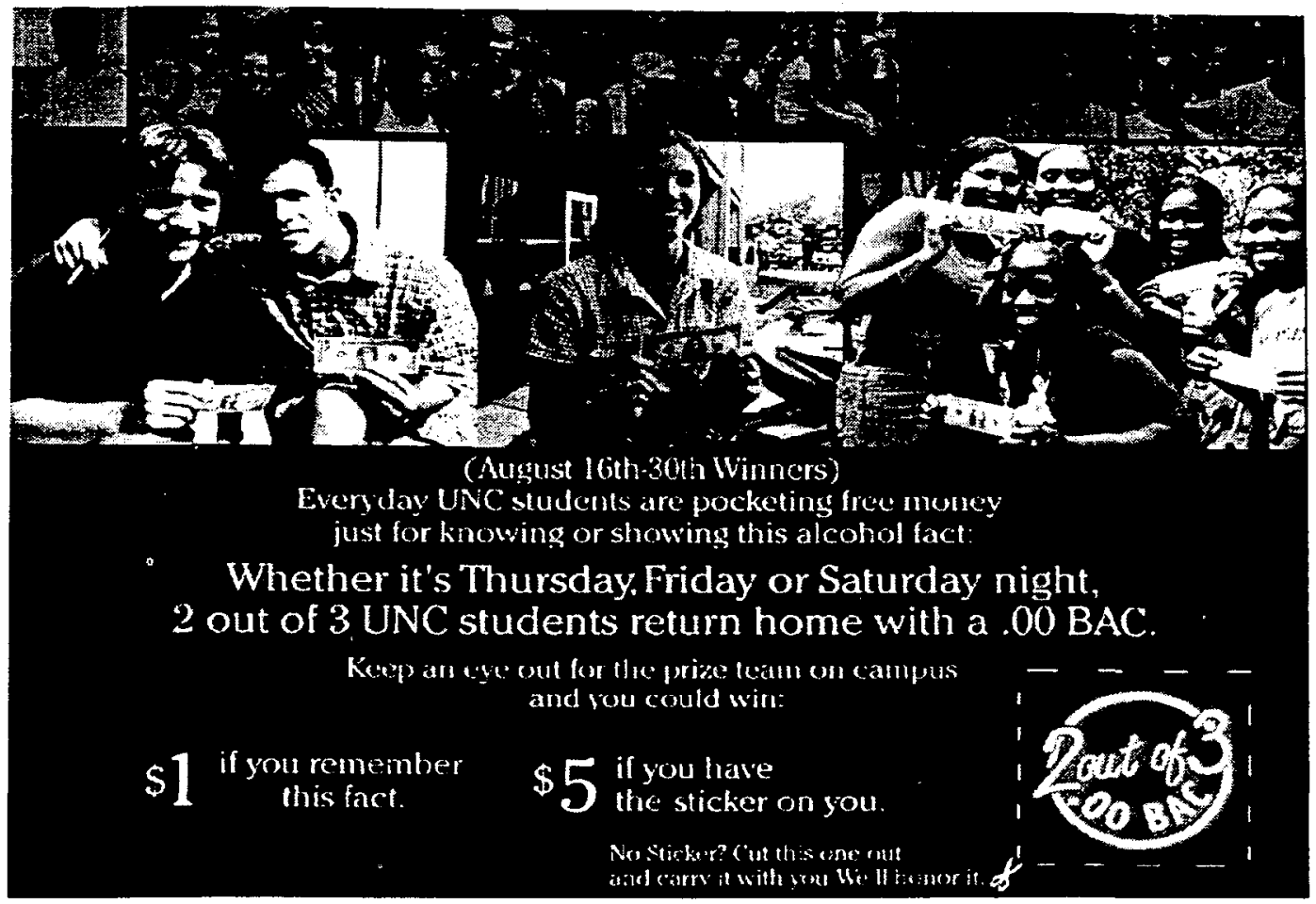

Figure 3.9 Second student newspaper advertisement.

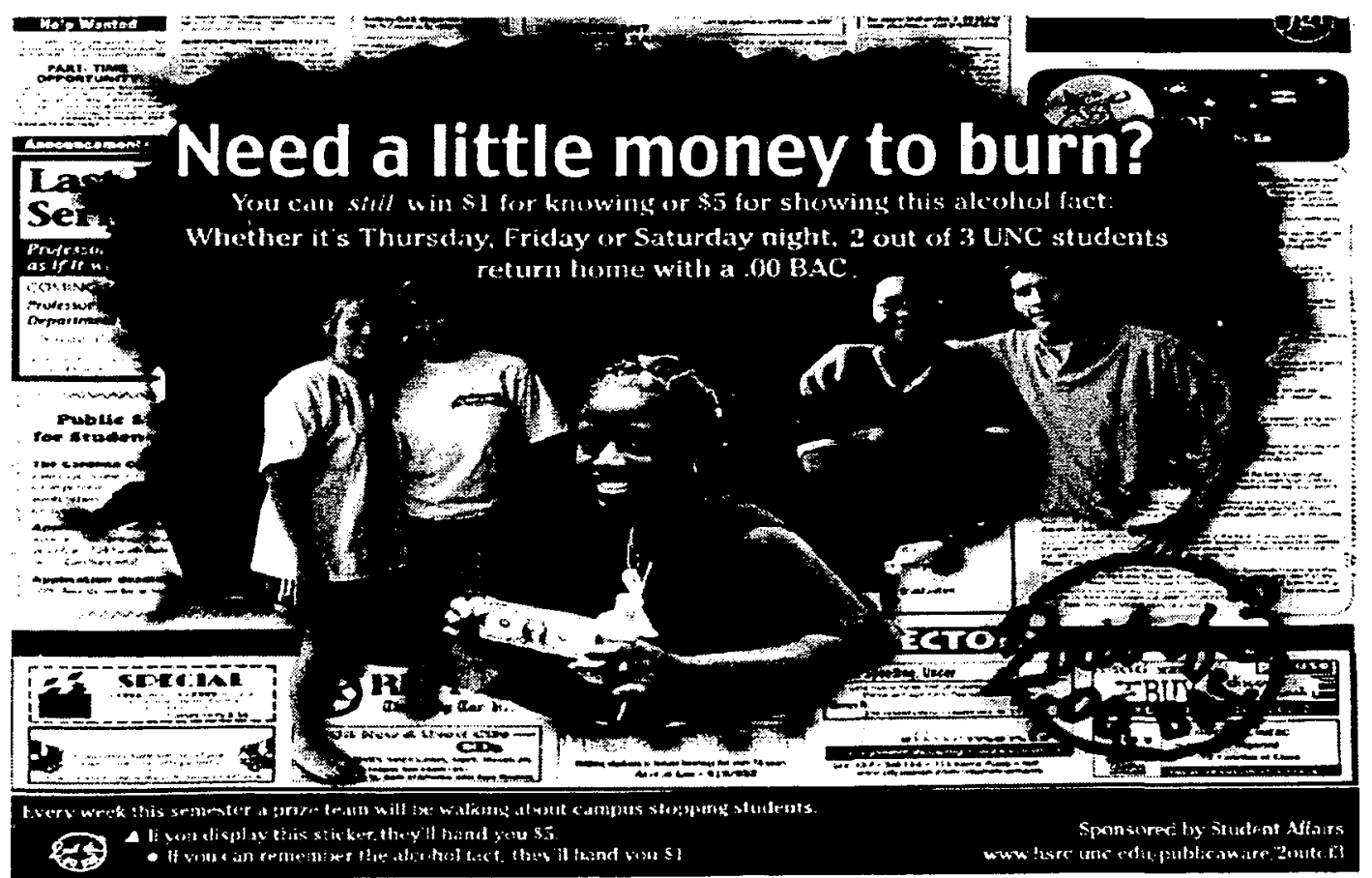

Figure 3.10 Third student newspaper advertisement. 
Web site. A web

site was created to provide feedback to students to ensure they realized that we were following up on the promise to reward students for having the poster up in the rooms. Pictures of weekly winners were posted on the site (see Figure 3.11). The web site also provided basic information about the program for those who may not have learned about it elsewhere. The web site address was

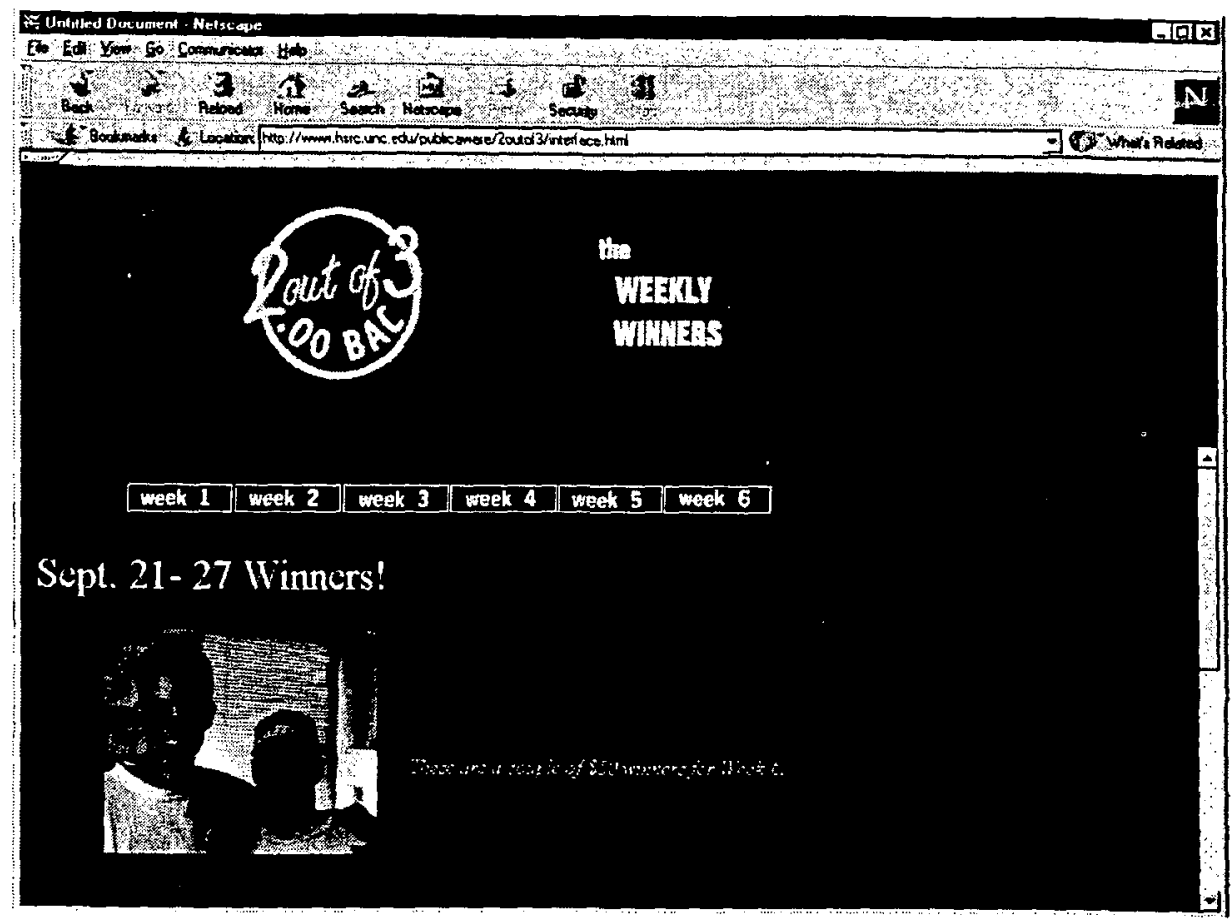

Figure 3.11 Screen shot from web site showing feedback made available to students about the " 2 out of 3 " program included on all program materials.

\section{Impact of data collection activities on awareness}

A particular strength of basing the norms program on data from BAC surveys is that they are highly visible to students. In contrast to typical mail questionnaire surveys, which are invisible to nearly everyone except the participants, when BAC survey data are being collected, a large majority of the student population becomes aware of the survey. The first data collection, which provided the facts for the development of the messages, occurred in the Fall of 1997, prior to any program activity. The second round of data was collected in the Fall of 1999, after the majority of the students had been exposed to the alcohol fact. Three teams per night moved around campus to collect data. As a result, a substantial proportion of students actually participated and many more saw interviews in progress. Hence it was more difficult to deny the validity of results from such a survey than it was to question the results from a relatively small mailed questionnaire survey. It is likely that the high visibility of the data collection contributed both to the overall awareness of the program and the credibility of the fact. 


\section{Follow-up BAC Survey}

Research on social norms approaches to drinking on college campuses indicate that they result in a reduction in student drinking (Haines, 1996; Johannessen et al., 1999). However, because of the mechanism by which the social norm approach produces effects, these changes tend to be gradual. Over a six year period, Haines (1996) found roughly a $3 \%$ yearly decrease in self-reported "binge" drinking among students at Northern Illinois University. Since we expected only a small change during the first year of the program, we designed the follow-up survey to examine student awareness and understanding of the program, as well as the ultimate criterion of drinking.

The " 2 out of 3" program is designed to become a permanent part of the ongoing alcohol awareness program at UNC-CH, thus allowing sufficient time to produce the desired behavioral changes. While outside funding for the project was completed in March, 2000, the program will continue as part of UNCCH's ongoing alcohol programs for the 2000-20001 academic year. Figure 4.1 presents the timeline of the project to date.

\section{Table 4.1}

Timeline for "2 out of 3" Project

Fall 1997

Academic year 1998

May-August 1999

August-December 1999

October 1999

January-May 2000

May 2000
Initial round of BAC data collected

Data analyzed, partnerships formed and program developed.

Program begins with presentations to incoming first-year students during CTOPS sessions

Full campus-wide program in place

Poster incentive campaign

Sticker incentive campaign

News Conference

Newspaper ads

Website

Second round of BAC data collection

Maintenance phase of campus-wide program

Poster and sticker campaign continued at reduced level

Newspaper ad with results of 1999 data collection

Begin 2000-2001 program 


\section{Study Design}

During the fall of 1999, the BAC survey was repeated using the same procedures employed for the original 1997 survey. This was conducted at the same time of the semester as the 1997 survey to minimize effects due to possible changes in drinking throughout the course of the semester. As a result of somewhat better weather, and because of experience with the original survey, we were able to obtain a greater number of interviews during the same time period. Data were weighted to adjust for oversampling of Thursday, Friday and Saturday nights.

\section{Characteristics of sample}

As can be seen in Table 4.1, the basic demographic make-up of the 1999 sample was quite similar to that in 1997, which is to be expected given that the same procedures were used. The one noteworthy difference is that -males were a slight majority in the 1999 sample, with 4\% more than in the 1997 sample. The 1999 sample was also somewhat younger, with $3 \%$ more respondents under the legal drinking age.

\section{Program awareness}

Because a program to promote accurate understanding of campus drinking norms would not be expected to have a dramatic, immediate effect on drinking behavior, the issues of primary interest in this survey concern how extensively the message reached the target population and how well it was understood. Unlike most messages, a norms message is not prescriptive. That is, rather than directly telling individuals what they ought to do, a norms message simply helps to correct a particularly important perception, that itself sends an indirect prescriptive message. Hence, even if a large proportion of the target audience has heard, and remembers a normative message, no measurable effect is likely unless the implication of that information is recognized by individuals. Accordingly, we asked several questions during the interview about student awareness of the " 2 out of 3" information, how they had learned about it, what they thought it meant and whether they believed it (a copy of the questionnaire is included in Appendix 4.a.).

Among 2,535 students interviewed, 2,279 were asked whether they had heard of the " 2 out of 3" program. ${ }^{8}$ Well over two-thirds of those interviewed (71\%) had heard of the " 2 out of 3 " campaign. The primary initial target of the program was first-year students. In particular, the two program elements designed to directly reach individual (the orientation presentation and posters distributed to individual rooms) focused on first year students. Other elements targeted the campus community generally rather than individuals. Among those who identified themselves as freshmen, 92\% had heard of the program. This compares with $60 \%$ of Sophomores, Juniors and Seniors $(p<.01)$.

8 An abbreviated set of questions was asked of some individuals (for example, those who indicated they were in a hurry). 
Table 4.2

Characteristics of 1997 and 1999 samples (percent).

\begin{tabular}{lcc}
\hline Characteristic & 1997 & 1999 \\
\hline \hline Freshman & 34 & 33 \\
Sophomore & 26 & 30 \\
Junior & 21 & 21 \\
Senior & 16 & 14 \\
Graduate/Fifth year & 4 & 2 \\
\hline Male & 49 & 53 \\
Female & 51 & 47 \\
\hline White & 84 & 82 \\
Black & 10 & 11 \\
Other & 6 & 7 \\
\hline Greek* & 25 & 24 \\
Non-Greek & 75 & 76 \\
\hline 18 - 20 years old & 78 & 81 \\
21 or older & 22 & 19 \\
\hline & $\mathrm{n}=1,841$ & $\mathrm{n}=2,535$ \\
\hline * Member of social fraternity or sorority & \\
& & \\
\hline
\end{tabular}

\section{Sources of information about program}

Those persons who indicated they knew about the " 2 out of 3" program were asked where they had learned about it. Their responses were coded into several categories shown in Table 4.3. Because first year students were a primary target, responses are broken out separately for freshmen. Respondents were prompted to mention all sources through which they had learned about the program rather than only one, so these categories are not mutually exclusive.

The program was designed to reach the student population through multiple, mutually supportive channels with the hope that this information would take on a more normative "feel" than a message that comes only from a single source. Accordingly, it is interesting to look at these reported information sources in some detail. Table 4.3 shows the percent of persons who mentioned each of the various channels by which students learned about the " 2 out of 3 " fact. 
Table 4.3

Source of information about " 2 out of 3 " fact by class year (percent)*

\begin{tabular}{lcccc}
\hline Information source & $\begin{array}{c}\text { All Respondents } \\
(\mathbf{n = 1 , 6 0 2})\end{array}$ & $\begin{array}{c}\text { Freshman } \\
(\mathbf{n = 6 9 2 )}\end{array}$ & $\begin{array}{c}\text { Other student } \\
(\mathbf{n = 9 1 0})\end{array}$ & $\begin{array}{c}\text { Probability } \\
\text { value }\end{array}$ \\
\hline CTOPS (orientation) & 33 & 72 & 3 & $<.01$ \\
Poster & 46 & 63 & 32 & $<.01$ \\
Sticker & 19 & 19 & 19 & n.s. \\
Newspaper ads & 24 & 6 & 39 & $<.01$ \\
Television & 2 & 1 & 3 & n.s. \\
Web site & 1 & 0 & 2 & n.s. \\
Friend & 14 & 10 & 18 & $<.01$ \\
"Prize patrol"** & 5 & 6 & 5 & n.s. \\
Fall Fest*** & 2 & 2 & 2 & n.s. \\
\hline \hline
\end{tabular}

* Columns do not sum to $100 \%$ because individuals cited multiple sources.

** The "prize patrol" refers to the project staff members who visited campus looking for posters and stickers in exchange for the promised rewards. When talking with a group about the stickers and the " 2 out of 3 " fact, they became a source of information about the program for those who had not yet heard about it.

*** Fall Fest is the campus-wide celebration held on the Sunday night before fall classes begin. "2 out of 3" stickers were handed out by project staff at this event as one way of reaching students, other than freshmen, early in the semester.

It appears that there were five productive channels for message distribution. Seventy-two percent of first year students recalled the " 2 out of 3" message from their orientation session. Given that all first year students are required to attend an orientation session, it is somewhat surprising that only about threequarters reported hearing the " 2 out of 3 " message there. Part of the slippage is probably due to inattentiveness during the session; another part probably results from the fact that a number of students were late to the opening orientation session where the " 2 out of 3 " message was presented early in the program. The $3 \%$ of older students who reported hearing the " 2 out of 3" information at orientation probably results from their attendance at an orientation session that was held for transfer students.

Nearly two-thirds $(63 \%)$ of first year students reported seeing a " 2 out of 3 " poster. This was precisely the purpose of first making it available to as many freshman students as possible by putting it on the bed in their residence hall room before they checked in, then using the prospect of a financial reward to induce them to actually put it up in their room (so they and others would see it). The fact that $32 \%$ of students who would not have had a poster themselves saw one attests to the success of this mechanism for getting the word out. Reports of seeing the poster clearly indicate the age-grouping of students on campus. Whereas $39 \%$ of Sophomores reported learning about the " 2 out of 3" program from a poster, that declined to $25 \%$ of Juniors \& Seniors $(\mathrm{p}<.01)$. 
Another indication of the extent to which the poster was displayed in student rooms comes from records kept by the "Prize Patrol" when they visited randomly selected rooms each week to hand out $\$ 50$ to persons who had the poster displayed in their room. Since rooms were visited randomly, it is possible to estimate the proportion that had a poster displayed from the number of rooms visited before a poster was found. For example, if all rooms had a poster, then the first room visited would always receive an award. If $50 \%$ of rooms had a poster displayed then, on average, two rooms would have to be visited before finding a poster. During 7 of the first 8 weeks of the program, the very first room visited had displayed the poster, suggesting that nearly $90 \%$ of freshman residence hall rooms had the poster displayed. During the next 8 weeks, the display rate declined to around $42 \%$. During the spring semester more than a third of rooms (37\%) continued to display the poster. ${ }^{9}$

It is surprising how few first year students reported seeing anything about the program in the student newspaper. Whereas nearly four in ten (39\%) older students reported learning about the program from the newspaper, only $6 \%$ of freshmen mentioned that source of information $(p<.01)$. It may be that with so many other more salient sources of information, first year students simply forgot that they had also seen something in the newspaper. Alternatively, it may be that this group of students had not yet gotten into the habit of reading the newspaper regularly -- only three ads were run throughout the semester.

An interesting finding that again points to the effectiveness of the efforts to generate discussion about the program through various mechanisms is that nearly one in five (18\%) Sophomore, Junior and Senior students mentioned hearing about the program from a friend. This clearly suggests that the information was delivered in a non-passive fashion. Program elements appear to have stirred up discussion among the target group. This is critical for a norms campaign, because social norms are embedded in the everyday lives of individuals; they don't reside in formal messages, emerging instead from social interaction. Evidence in the present case seems to indicate that we have made steps in the direction of the amount of student drinking being a topic of discussion. Moreover, that discussion now revolves, in part, around the " 2 out of 3" fact that we discovered, rather than only the myths that existed previously.

\section{Message understanding}

As mentioned earlier, it is important for persons to understand the implication of the simple factual information that is at the core of a social norms program. To assess this, during the BAC survey we asked respondents who had heard about the " 2 out of 3 " program "What do you think the message of the campaign means?" Responses were coded into four categories: Understood the point of the fact (e.g., that drinking is less common than people think, there is less pressure to drink etc.), misunderstood it (e.g., drinking is dangerous or illegal, the university is cracking down on drinkers), didn't know, or simply responded that they didn't believe it without explaining what they thought it meant. Seventy percent of respondents were coded as having understood the general point that drinking norms are different (or

9 This excludes rooms where nobody was home since it was not possible to determine whether a poster was displayed or not. Even if it is assumed that all persons not home had not displayed the poster, we estimate that approximately $67 \%$ of rooms had the poster displayed during the initial 8 weeks. 
associated pressures to drink are les:

e iypically thought to be the case on the UNC-CH campus.

Reflecting their greater exposure to thic point of the message through the orientation sessions, and perhaps greater discussion of the fact with parents and/or friends as a result, freshmen were more likely than older students to understand this point ( $78 \%$ vs. $64 \%, \mathrm{p}<.01)$.

\section{Message belief}

Heavy media coverage of alcohol-related tragedies typically lead readers to believe that drinking and driving is more common than is actually the case. As a result, it is not unusual for individuals to view the results of BAC surveys with some skepticism. We expected the student BAC survey results to be met with skepticism as well. When initially told of our findings about student drinking, nearly everyone - media representatives, other researchers, members of the general public, individual students - was surprised, if not disbelieving. Many questioned the methodology until learning the care with which the study was conducted. Hence, we were not surprised to learn that a substantial proportion (54\%) of students did not believe " 2 out of 3" accurately represented student alcohol use at UNC-CH. Another $11 \%$ were unsure, leaving only $35 \%$ who thought the " 2 out of 3 " fact was accurate.

Interestingly, Seniors were more likely to believe " 2 out of 3 " ( $47 \%$ vs. only $32 \%$ of other classes, p < $.01)$. This is despite the fact that Seniors in this sample reported as much drinking and had similar measured BACs similar to those from other class years. Hence, this difference in belief about campus drinking norms may reflect a maturing of students who have spent three years in college, with the somewhat greater perspective that brings.

\section{Believers vs. non-believers}

We were not surprised by the substantial proportion of respondents who expressed skepticism that twothirds of UNC-CH students have little or nothing to drink on traditional "party nights." Nonetheless, it is a concern that needs to be addressed. Before attempting to deal with this disbelief, we examined characteristics of those persons who were most likely to indicate they didn't believe the " 2 out of 3 " fact.

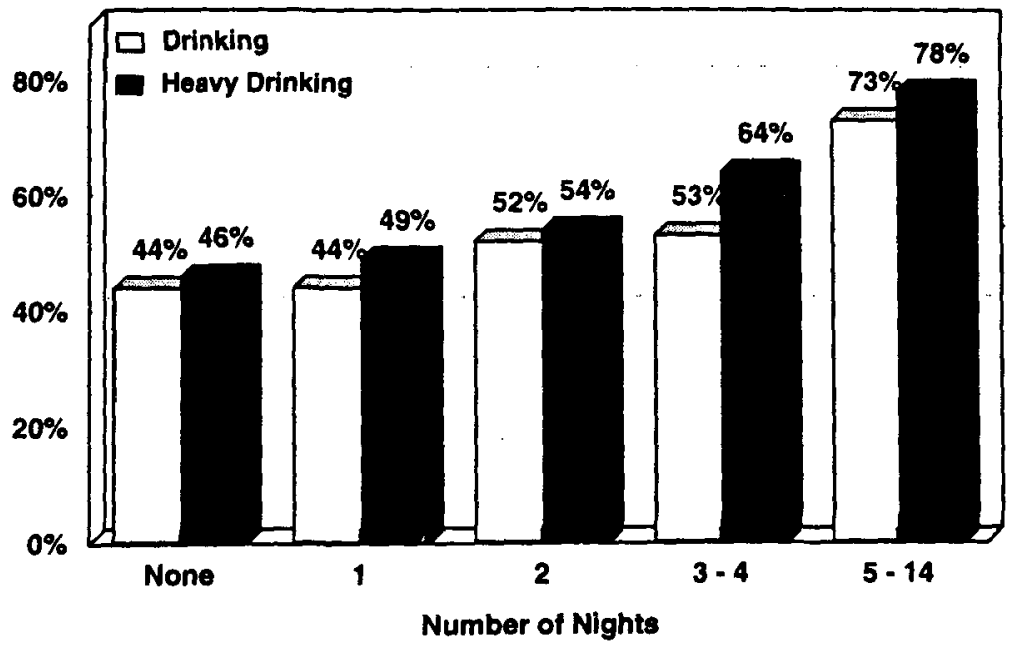

Figure 4.1 Non-belief in Accuracy of " 2 out of 3" by Number of Drinking and Heavy Drinking Nights in Past Two Weeks

Those who did not believe that " 2 out of 3" is an accurate representation of UNC-CH are the more extreme drinkers (not merely drinkers or occasional heavy drinkers). Belief in the accuracy of " 2 out of 3 " is related to number of drinking nights and heavy drinking ( $>5$ drinks) nights during the past two weeks, as shown in figure 4.1. In addition, persons who had consumed the greatest amount of alcohol (measured by multiplying the number of drinking occasions in the past two weeks by the typical amount consumed) 
were less likely to believe the accuracy of " 2 out of 3." Among those in the upper quartile of alcohol consumption, $73 \%$ were non-believers vs. $49 \%$ of those who drank less or not at all in the past two weeks ( $p<.01$ ). Looking at measured drinking and acceptance of the " 2 out of 3" fact, those who had a BAC above .08 when we interviewed them were more skeptical than those with a lower or $.00 \mathrm{BAC}(68 \%$ vs. $53 \%, \mathrm{p}<.02$ ). Also of interest is that in every analysis, those persons who were in the lighter drinking category - whether measured as amount, number of times, or simply being in a category that drinks less were more likely to indicate that they were unsure whether " 2 out of 3" was accurate rather than stating definitively that the believed it was true or not.

Another indication of how those who believed that the fact is accurate are different from those who don't is that non-believers were more likely to have begun drinking at an early age ( 15 or younger). Whereas $67 \%$ of those who began drinking by age 15 did not believe " 2 out of 3" was accurate, only $52 \%$ of those who started drinking at a later age found this fact hard to believe $(\mathrm{p}<.01)$. Among those who did not begin drinking until they had reached college age (18) only $46 \%$ did not believe the fact was accurate.

A particularly interesting finding is shown in Figure 4.2. When we compared the BAC distributions on weekend nights (Thursday - Saturday) for persons who did not believe "2 out of 3" was accurate, $68 \%$ of them had a $.00 \mathrm{BAC}$ when we interviewed them. That is, as a group, the non-believers evinced the very thing they found difficult to believe.

In an effort to begin addressing student disbelief about the veracity of " 2 out of 3," we created a full page newspaper ad to provide feedback to students about findings from the 1999 survey (see Figure 4.3). In addition to detailing the survey method (e.g., time and place of interviews, number of interviews) and characteristics of

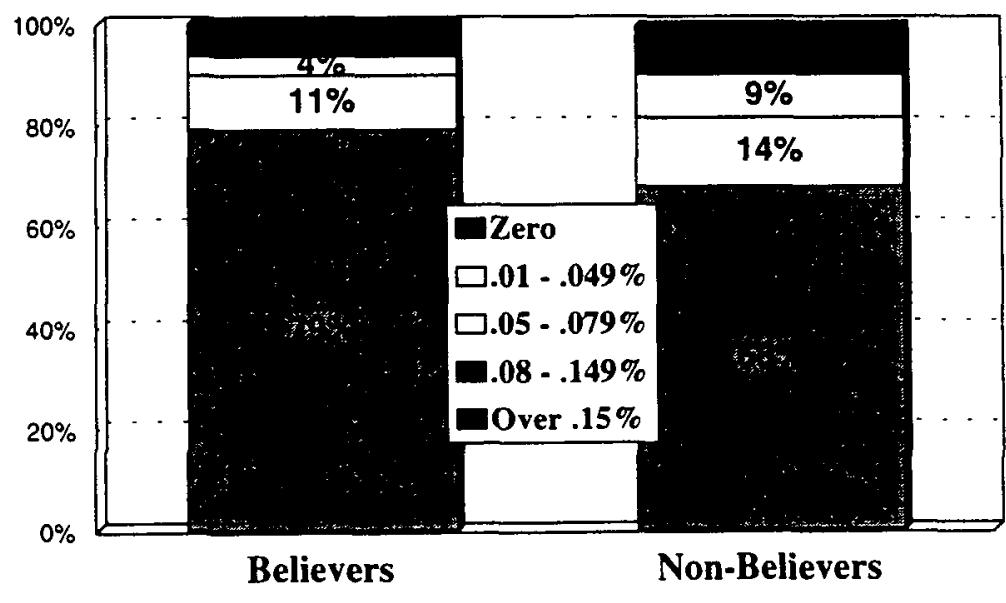

Figure 4.2 BAC distributions comparing those who believed the " 2 out of 3" fact was accurate with those who did not. persons interviewed (e.g., age, percent male vs. female, percent Greek vs. non-Greek) this ad highlighted the basic BAC distribution for party nights. It also included a mention of the "strange but true" fact that among non-believers, the BAC distribution was almost exactly "2 out of 3" with no alcohol the night they were interviewed. Unfortunately, since this ad was based on the second (1999) survey data, we have no information on what effect it may have had on students' beliefs. 


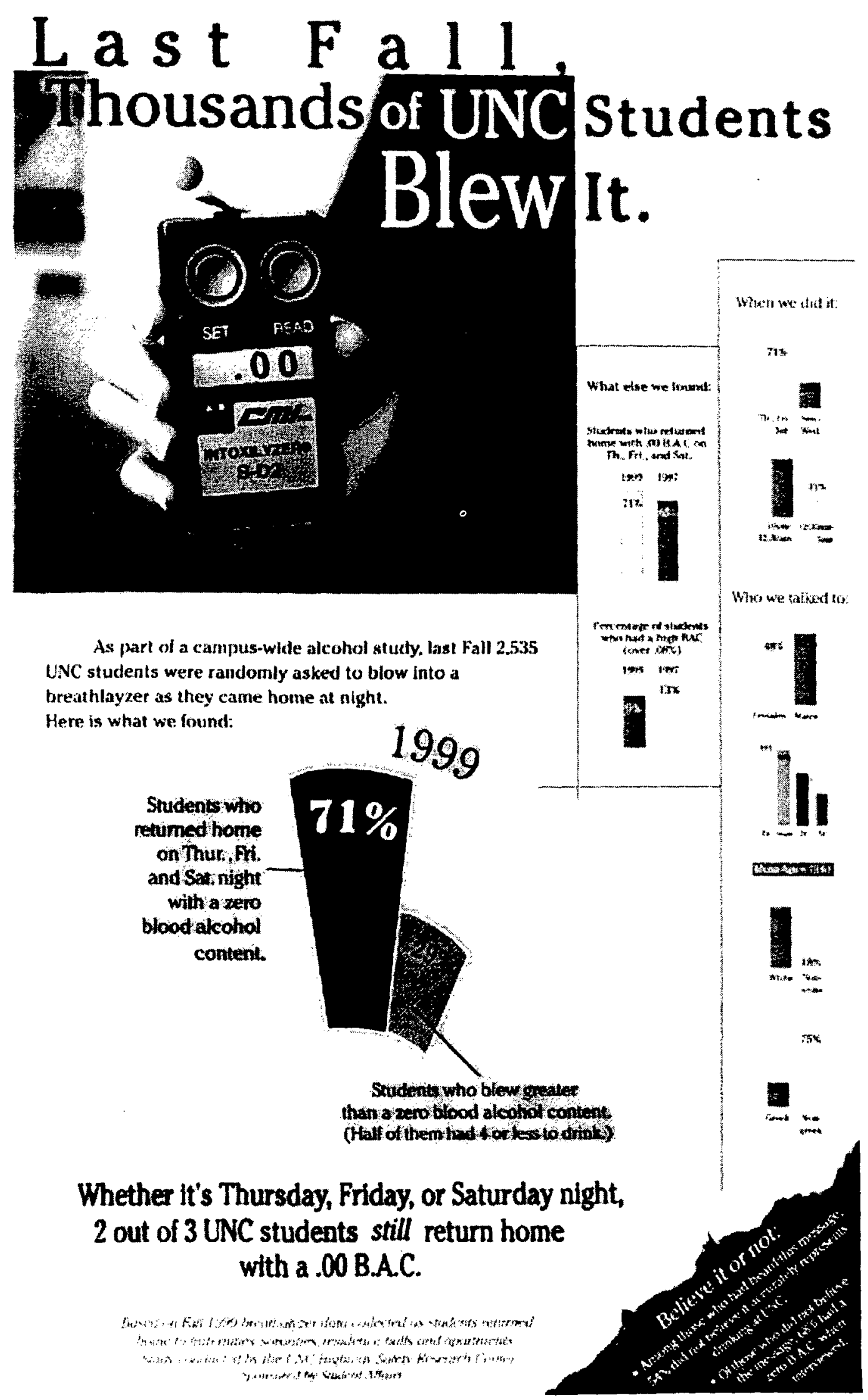

Figure 4.3 Student newspaper ad to provide feedback to students about results of 1999 BAC survey 


\section{Direct evidence of program effects}

Although it is not possible to cleariy attribute changes in student behaviors between 1997 and 1999 to any intervention, since we do not have a control group, it is instructive to see whether changes have occurred. Internal analyses of the data may help to isolate reasons for any changes that are detected.

\section{Measured Drinking}

Table 4.4 shows the proportion of students found to have a positive BAC as well as BACs above .08 and .15. It is clear that student drinking declined from the fall of 1997 to the fall of 1999. It appears that heavier drinking declined more than the act of drinking. The decrease in very high BACs $(\geq .15)$ is not statistically significant, although the proportion of respondents with BACs in that range is so small that it would be difficult to obtain a statistically significant effect with anything less than a major change in behavior. ${ }^{10}$

\section{Table 4.4}

Percent of respondents with $\mathrm{BAC}$ above three thresholds.

\begin{tabular}{lcccc}
\hline BAC & 1997 & 1999 & $\begin{array}{c}\text { Percent } \\
\text { decline }\end{array}$ & $\mathbf{p}$ \\
\hline$>.00$ & 23.7 & 21.5 & 9.3 & $<.10$ \\
$\geq .08$ & 10.7 & 8.3 & 22.4 & $<.01$ \\
$\geq .15$ & 1.9 & 1.3 & 31.6 & $>.15$ \\
\hline & $\mathrm{n}=1,786$ & $\mathrm{n}=2,451$ & & \\
\hline
\end{tabular}

Subgroup analyses found declines in positive and high BACs $(\geq .08)$ in virtually every subgroup, although many of these were not large enough to be considered statistically reliable. There were no statistically significant changes among males, but females were less likely to have a positive BAC $(\mathrm{p}<.05)$ and a BAC $\geq .08(\mathrm{p}<.01)$. Within racial subgroups, whites showed a decline in BACs over .08 ( $p<.01$ ) but there were no other significant changes. There were declines at both levels among Greeks and non-Greeks alike, but only the decrease in BACs above .08 among Greeks was statistically significant ( $p<.02$ ). Examining class years, only the declines among Sophomores were large enough to reach traditional levels of statistical significance $(\alpha=.05)$. This finding was paralleled by a significant decrease among persons age 19 .

When looking at self-reported heavy drinkers (i.e., those who reported having 5 or more in a row at least once during the past two weeks), there was a significant decline in the proportion who had a measured BAC above .00 the night they were interviewed (from $19 \%$ to $13 \%, p<.01$ ). Similarly, those

10 Even with the rather large sample sizes in the present study, we only had statistical power of $\beta=.74$ to detect a $50 \%$ decrease (i.e., from $1.9 \%$ to $.095 \%$ ) using a 2-tail significance test at $\alpha=.05$. 
who reported frequent heavy drinking (five or more on at least 3 occasions) also were less likely to have a BAC over .08 (declining from 25\% in 1997 to $19 \%$ in $1999, \mathrm{p}<.05$ ).

\section{Drinking driving}

Changes in the BACs of persons who reported they had driven (or who were interviewed as drivers) showed the same decrease found among students in general. The proportion of drivers with a BAC of .08 or higher declined from $2.6 \%$ to $1.3 \%(\mathrm{p}>.21)$ and the proportion with any measurable alcohol declined from $13 \%$ to $9.7 \%(p>.18)$. These changes are not statistically significant, but a relatively small number of drivers were interviewed. Given that the magnitude of these changes is consistent with those among students in general, it is probable that this lack of significance is due to the relatively small sample size.

\section{Change in self-reported behavior}

Student perceptions of their drinking in comparison to that of the "typical" UNC-CH student moved only slightly in the direction to be expected. These were not statistically significant in any subgroup, including the one group where such a change should have been most apparent - first year students. There was no change in self-reported heavy drinking or frequent heavy drinking. Finally, reports of any drinking and number of drinks also remained the same.

\section{Indirect evidence of program effects}

Official reports of alcohol-related incidents are systematically collected at UNC-CH. The three most pertinent of these are: (1) Alcohol-related incidents in and around residence halls, which are reported to the Department of Housing and Residential Education, (2) on-campus incidents not involving residence halls, which are reported to the Office of the Dean of Students, and (3) off-campus incidents that come to public attention (e.g., by report to local police), which are reported to the Center for Healthy Student Behaviors. Table 4.5 shows the change in incidents from the Fall 1998 to the Fall 1999 semesters. ${ }^{11}$ Although there are a variety of possible explanations for these dramatic decreases, as a result of changes in various university programs, policies, and enforcement activities, they have been attributed to the " 2 out of 3" program by the Vice Chancellor for Student Affairs in her recent report to the Board of Trustees.

11 There was a change in reporting of off-campus incidents that prevents a meaningful a comparison of the offcampus data from 1998 to 1999. In 1999, incidents at a large, private residence hall were added to the report, making a comparison inappropriate. 
Table 4.5

Number of alcohol-related student incidents reported to university authorities

\begin{tabular}{lccc}
\hline Incident type & Fall 1998 & Fall 1999 & Percent decline \\
\hline \hline On Campus - Residence Hall & 160 & 83 & 48 \\
On Campus - Other Location & 85 & 74 & 13 \\
Off Campus & 76 & $\ldots$ & $\ldots$ \\
\hline \hline
\end{tabular}




\section{Discussion and Conclusions}

The goal of the project described above was to learn more about college student alcohol use by conducting a "first-of-a-kind" BAC survey of a representative sample of students, then to use that information to develop a program to reduce excessive drinking as well as drinking-driving by students on a single campus.

\section{Novelty and benefit of using BAC data}

The use of directly measured BAC data was particularly valuable in several ways. First, our plan to obtain BAC measurements was a strong selling point for the project with campus administrators. Although there were concerns about this unusual approach to studying student drinking, there was also great interest in having a substantial data base with objective information about student alcohol use. The perceived advantage of such information was based on a genuine desire to know more about the issue and, therefore, to be able to direct programs and resources appropriately.

Another benefit of having BAC information is that there was greater flexibility in developing the social norms message. On other campuses that have created social norms programs, program developers have been severely constrained in the kinds of information they can provide to students as evidence of normative behavior. As a short-term program, messages that state something like "When they party, $\mathrm{xx} \%$ of UNC students have four or fewer," are perfectly appropriate. However, social norms are not based only on "poster factoids." Norms are evident in many ways in the social environment. For a program to "engineer" a correct perception of a norm, it needs to become richer, more diverse and more enduring than can be accomplished by repeating, year after year, the same basic message. Evidence available from the BAC survey can easily serve that purpose. In addition to generalized information about self-reported drinking, it is possible to use situation-specific information, as was the case in the first year of the " 2 out of 3" program. Because situation-specific data were collected, it will also be possible to craft messages about drinking-driving, drinking in bars, drinking at parties - all related to BAC values or to self-reported drinking, or both. Designated driver messages can be created as well. For example, messages like "When they had been drinking, 99 out of 100 UNC students did not drive with an illegal BAC," are possible. Similar messages can, of course, be developed based on self-report data. However, because of the general nature of the questions typically asked, in combination with individual misunderstandings of impairment and DWI laws, the data may be unable to support normative messages that are as compelling as those afforded by the BAC data.

A particular strength of having BAC data was that the social norms program that resulted had the potential to be far more credible than typical norms programs. BAC data currently are noteworthy - both to the media and the target population - because they are so unique. They are unique both in their objective quality and in the way they are obtained (time-specific personal interview rather than retrospective account in response to mailed questionnaire). This is important, since a message to students 
(or others) that drinking is not so extensive as most everyone seems to believe is likely to be disputed. In the present case, numerous individuals who have learned about the BAC survey have been skeptical of the method, simply assuming that it was somehow defective. ${ }^{12}$ However, in contrast to the typical survey upon which social norm messages are usually based, the BAC survey is more difficult for students to question. ${ }^{13}$ Because the operation is highly visible to drinkers, they know that it is taking place. A substantial proportion of the student population (about 18\%) participated in the survey and many more observed the interview teams moving around campus and saw interviews being conducted. Consequently, belief in the veracity of the " 2 out of 3" fact may have increased after the Fall 1999 survey. Until the survey was conducted, no first or second year student had seen first-hand evidence of the data collection, so it was only members of the Junior and Senior classes who had known about the survey from which the " 2 out of 3 " information was drawn. This may help to account for the greater tendency among Seniors to believe " 2 out of 3" accurately represents drinking among UNC-CH students.

Another benefit of having collected BAC data is that they provide a solid set of information against which to evaluate the effects of programs - both the social norms program described here as well as other initiatives that may occur in the future. The finding that several self-reported measures of alcohol use did not change while objective measures of drinking declined suggests that self-report data may be relatively insensitive to changes in drinking behavior. It is not clear why this would be the case. It may have to do with the fact that self-report information is probably not very precise when it comes to actual amount of alcohol consumed, even if number of "drinks" consumed can be accurately recalled and reported. For example, in 1999 students may have been drinking at a somewhat slower rate, so that the same number of drinks would not produce such high BACs. Or the alcohol content in their drinks may have been somewhat lower, or there may have been fewer instances of drinking from common containers (e.g., kegs) so the "drinks" they had were on average not so large. Whatever the explanation, it is clear that heavy drinking, as measured by BAC values, declined and that was not reflected in any of the self-report data.

Yet another benefit of the approach used here to learn about college student alcohol use is that it has helped to broaden our understanding of student drinking. It may also have contributed to the national debate about the most desirable approach to addressing student drinking. Promoting awareness of normative behavior is a relatively new approach. A more traditional approach is to use urgent messages about the dangers of student drinking, citing data that can exaggerate the extent of alcohol-related problems among students. During the fall of 1999, findings from the present study were cited by advocates of the normative focus in several forums on this issue. As noted above, reporting frightening (and sometimes misleading) statistics about student drinking may exacerbate the problem rather than help to reduce it. In the past, making the case that student drinking was a problem that needed to be addressed may have required quoting attention-getting figures. In the current climate it seems no longer to be the

12 Upon learning about the details of the approach, this skepticism usually evolves into amazement that common beliefs about the nature and extent of the problem differs so much from the objective information.

13 College students are highly skeptical of the widely discussed phenomenon of "binge drinking." That may be due in part to defensiveness on their part, but they also are quick to point out that the standard measure of 5 drinks in a row is defective for failing to take into account the time period over which those drinks were consumed. BAC data cannot so easily be questioned on the basis of defective measurement. 
case that university administrators (or anyone else) are unwilling to admit that there is a problem with alcohol use on campuses in the U.S. Hence, there is less need to cite eye-catching statistics, which may inadvertently suggest the problem is larger than is actually the case.

Since we only have BAC data for the UNC-CH campus, it is not possible to address college student drinking in general. It does seem reasonable, however, to infer that the kinds of differences we found between the impression created by self-report data and that based on measured BAC data might be found on other campuses as well. It is important to recognize that we don't consider the BAC data to be "correct," while other sources of information are wrong. Rather, these data help to broaden our understanding of student drinking, providing a richer picture than can be had only from self-report information and data concerning relatively rare incidents (e.g., alcohol-related deaths or injuries).

It should be noted that at the time this project was proposed four years ago, few thought that a campus would be willing to expose themselves to this form of data collection. Apprehension about what student BAC data would show was high among college administrators. This has changed and universities and colleges are relieved to hear the results of the UNC-CH project. It is our hope that the positive outcome this data coilection has had for the UNC-CH campus will assist other campuses in deciding to collect similar data. The data and the project received accolades from the Board of Trustees and several favorablearticles about the study appeared in local and national print media. Once there is a base of data from multiple campuses, researchers and practitioners will be better able to address college student drinking in general.

\section{Importance of an integrated program}

Another somewhat unique feature of the UNC-CH social norms program is the extent to which multiple program elements were woven together in a set of mutually reinforcing components. Several different channels were used to reach the ultimate population - undergraduate students at UNC-CH. The choice to focus initially on first year students was based on indications that they are most vulnerable, but also on evidence that they might be easier to convince with information that goes counter to commonly held beliefs. This group was then reached directly through two interconnected channels: A live, interactive presentation to convey an unusual message endorsed by students in their own words and a poster to be put up in students' rooms, along with a financial incentive for doing so. By also making "miniature" posters (i.e., the "2 out of 3" stickers) available to all students, along with potential rewards for displaying them, the principal fact was delivered to students via another channel. Moreover, by offering financial rewards for knowing this fact, we sought to increase the proportion of students who would make an effort to retain the information about normative behavior. Several aspects of all these efforts were consciously designed to increase the likelihood that the information would reach students and be retained by them.

In an unusual approach for a university program, we also reached out to the general community with the same information about normative behavior provided to students. Because we sought to undermine misperceptions of student drinking norms that are held by the general public, not merely students, we believe it was important to do this. It is well-recognized among college and university alcohol program 
professionals that alumni can present a problem. For example, caught up in nostalgia they may inadvertently try to sustain the alcohol climate of their era on campus, through word and deed. By spreading the drinking norm message to alumni and the general public, many of whom are parents of present or future UNC-CH students, we believe this program is planting the seeds of future success on campus by reaching off campus into the broader community.

\section{Program message recognition}

The responses of students surveyed during fall 1999 indicated that the program had an extremely high recognition rate ( $92 \%$ of first year students and $71 \%$ of the rest had heard of the program). Also, the vast majority of the students (78\% of freshmen and $65 \%$ of the rest of the respondents) understood the meaning of the message, characterizing it as meaning either that drinking is less common than people think or that there is less pressure to drink. Both the degree of recognition and the extent of understanding are quite high, especially since the program had been in place for a relatively short period of time. We believe the main reasons for the success in getting this information into the population has to do with the way the program was structured, with integrated mutually supportive elements. In addition, reaching this audience was easier than others might be because the UNC-CH student population is geographically concentrated, and has one major information source to which most students attend: the student newspaper.

This degree of message recognition and comprehension is exceptional for any public information campaign. This success should be examined to identify strategies that may be of value for any public information and education program. First, we believe that the amount of effort ( 6 rounds of testing) that put into crafting the wording of the message was an important factor. We sought a clear and compelling single statement that also reflected the media savvy the younger audience is accustomed to seeing in modern advertising. A second factor may be the steps employed to present that message in a credible manner. For example, the presentation to incoming first year students was enhanced by the inclusion of a video of candid comments from real students about the validity of the message. A third factor may be the use of an incentive campaign in which students were rewarded for knowing or displaying the message. Incentive programs are not new to highway safety programs. Many such programs were valuable as part of successful occupant protection programs in the 1980's.

\section{Non-believers}

The success of any information-based program is contingent on the target population receiving, understanding, and accepting the message. In the follow-up survey, we found a substantial amount of skepticism about the initial message. There are two issues here. The non-believers are that group we would most expect to disagree, since they live in a world where drinking is common and has been for some time. Although there may be some self-justification in their unwillingness to believe the fact presented, that is probably not the main issue. Since humans tend to think the world is like what they see around them, the " 2 out of 3" fact must seem way out of line to them. It doesn't represent their lives, or that of many of their friends. Or so it would seem. But the BAC distribution of non-believers in the follow-up survey was almost exactly the same as reported in the " 2 out of 3 " fact. So why don't they believe it? This may be because non-drinking is not nearly so salient as drinking when one thinks about 
the day, the night, the week. There is

ince of research that indicates individuals are not very good statisticians, that is, that they do ialy in judging the frequency with which things happen. This may simply be another manifestation of that phenomenon.

In the present case, and for other norms programs, the task continues to be to encourage students to see (and think about) things the way they really are. The lighter, less frequent, or non-drinkers are probably more inclined to accept the " 2 out of 3" fact since it more closely parallels their lives. Still, many of them don't believe it either and many of the heavier drinkers do. In efforts to persuade nonbelievers, it is important not to oversimplify or misunderstand the lack of confidence in the " 2 out of 3" fact. The variation within groups (e.g., heavier and lighter drinkers) is greater than the differences between them. It may be that the most effective way to counter non-belief is merely to sustain the approach over an extended period of time.

\section{Addressing the fact that drinking for many college students is illegal}

By stating that two out of three students return home with a $.00 \mathrm{BAC}$, we are also saying that one out of three students does not. This raises the question of whether that statement may help to legitimize underage drinking, especially since most undergraduate students are not old enough to drink legally. Similarly, one might also ask what impression is given by the statement that most of the drinkers have four or fewer drinks. In fact, we chose to use the .00 BAC fact as our primary message based on feedback from students who felt the " 4 or fewer drinks" message could be taken several ways.

It is important to understand that programs to emphasize campus drinking norms are not intended to replace the variety of other important elements of a comprehensive campus alcohol program. Because of its non-prescriptive nature, a social norms program can fit comfortably into a campus policy that prohibits alcohol possession on campus property, applies sanctions for alcohol-related transgressions, and provides treatment for persons who exhibit evidence of a problem with drinking (for example, by a DWI conviction). While a social norms message does not preach behavior change to the students, neither is it intended to encourage drinking. Rather, its purpose is to shake up the status quo. A desired outcome of the message is a reduction in the peer pressure felt by students who don't drink or who drink moderately. Because it is currently believed that drinking is more common than is the case, rather than encouraging drinking, a norms message helps reduce subtle, but strongly felt pressures to drink. Another desired outcome is to reduce the comfort level of those who abuse alcohol and to help undermine their expectation that others will accommodate their behaviors. Many students are reluctant to complain about the noise, property damage and other problems that individuals who abuse alcohol inflict on those around them. This program in intended to serve the purpose of correctly placing the power of the majority in the hands of the true majority - those students who typically drink little or nothing and return home with a .00 BAC.

\section{Encouraging news about drinking driving}

One of the motivations for this project was to reduce driving after drinking among college students via a reduction in drinking. One of the encouraging findings from the BAC surveys was that, despite their 
reputation as heavy drinkers, driving after drinking is uncommon among UNC-CH students. Years of messages encouraging persons not to drive after drinking appear to have made an impression on UNC-CH students, as they have on the driving public in general. In both the 1997 and 1999 surveys, drivers exhibited low levels of drinking at all. It seems clear then, that students on the campus studied are doing a good, if not perfect, job of separating drinking from driving. There remains room for progress, but the magnitude of this problem is less than was anticipated.

\section{Need to sustain program}

Social norms programs to reduce student drinking have shown great promise. Their conceptual underpinning is strong and, although limited, evaluation data presently available suggest that they do produce decreases in problem behaviors. It is important to keep in mind, however, that this approach is likely to produce changes incrementally rather than suddenly. Consequently, to be effective a norms program needs to endure. Haines (1996) and Johannessen et al., (1999) both report continuing declines in student drinking over a several year period. A conceptual analysis of the manner in which social norms operate suggests that is all that might be expected. However, unlike "one-shot" programs that might, with enough resources, produce a greater short-term change, the effects of a social norms program are unlikely to dissipate like those of most programs do. This is because once a more realistic conception of normative behavior concerning alcohol use has developed on a campus, it will tend to be self-reinforcing. As more students, administrators and faculty members recognize that excessive drinking is not particularly common, the tenor of discussions on a campus will change. More alternative activities not involving alcohol will become available, both through student initiative and through administrative efforts to foster an environment that is more supportive of students who do not wish to drink or to rely mainly on drinking for entertainment (e.g., greater availability of alcohol-free housing, extended hours at campus recreation locations). Subsequently, all these kinds of efforts and activities themselves become part of a social norms program. For this to occur, however, it is important to make a concerted, focused effort to promote the fact that most students behave responsibly most of the time with respect to alcohol. The various messages that the campus community and its surroundings receive about student drinking, via multiple channels, should be carefully coordinated so as to be mutually reinforcing. We believe that one such program is now in place and poised to grow at UNC-CH.

\section{Conclusions}

This project was an attempt to demonstrate that a technique used to study drinking and driving - the roadside BAC survey - could be modified and used productively to study drinking among college students. It is now clear that this approach is both feasible and useful. Information obtained from the survey was then used to develop a multi-faceted social norms program to reduce student drinking, as well as driving after drinking. The program clearly benefitted from having objective data on drinking to draw on. A follow-up BAC survey documented a high degree of awareness among the target population. It detected a decline in excessive drinking among students on the campus, but also found a substantial degree of skepticism among students about the norm identified by the research. 
As on most college campuses, a substantial proportion of students at UNC-CH report periodically drinking several drinks on an occasion. The results of the two BAC surveys indicate that despite this, even on weekend nights, a large majority of students have nothing to drink. Moreover, among those who do drink, reaching a high BAC is uncommon. These findings are both encouraging and a cause for concern. The fact that, on a typical night, nearly a quarter of students under the age of 21 have consumed alcohol is disturbing. On the other hand, the fact that less than $3 \%$ of students had BACs in the range that reliably produces observable signs of "drunkenness,"indicates that the problem is not as pervasive as many think. The finding that impaired driving, in this reputed heavy-drinking population, is rare and was similar to that found among the general driving population in North Carolina, even before the " 2 out of 3" program, is certainly encouraging.

Finally, the benefits of social norm programs to reduce reported drinking among students have been demonstrated previously. The present study provided the first opportunity to document whether, and how, actual drinking changes in response to a carefully designed and implemented program to highlight the fact that for the large majority of students, moderate drinking or abstinence - rather than excess - is the norm. Findings from the present study must be considered preliminary, but results are encouraging. Future research, using direct BAC measurement, needs to follow a social norms program over a period of several years. That will allow a more definitive answer to the question of whether the long term effects that social norm program have on self-reported drinking represent true changes in drinking, or merely changes in verbal behavior, as true drinking norms are recognized and understood by students. 


\section{References}

Bandura, A. (1977). Social Learning Theory. Englewood Cliffs, NJ: Prentice-Hall.

Beirness, D.J., Foss, R.D. \& Mercer, W. (1997). Roadside Breathtesting Surveys to Assess the Impact of an Enhanced DWI Enforcement Campaign in British Columbia. In C. Mercier-Guyon (Ed.) Alcohol, Drugs and Traffic Safety: Proceedings of the 14th International Conference. Vol 2: 955-962. Centre d'Etudes et de Recherches en Médecine du Trafic: Annecy, France.

Foss, R.D., \& Beirness, D.J. (1996). Drinking passengers and their drivers: Roadside Survey Results. In 40th Annual Proceedings, Association for the Advancement of Automotive Medicine. DesPlaines, IL.

Foss, R.D., Beirness, D.J., \& Sprattler, K. (1994). Seat belt use among drinking drivers in Minnesota. American Journal of Public Health, 88(11): 1732-1737.

Foss, R.D., Beirness, D.J., Wells, J.K., \& Williams, A.W. (1995). Roadside surveys in conjunction with sobriety checkpoints. In Kloeden, C.N. \& McLean, A.J. (Eds.) Proceedings of the 13th International Conference on Alcohol Drugs and Traffic Safety. Adelaide, Australia: NHMRC Road Accident Unit, University of Adelaide.

Glindemann, K.E., Geller, E.S., Clarke, S.W., Chevaillier, C.R., Pettinger, C.B. (1998). A communitybased feedback process for disseminating pedestrian BAC levels. Journal of Prevention and Intervention in the Community, 17(1): 55-68.

Goodman, R.A., Istre, G.R., Jordan, F.B., Herndon, J.L., Kelaghan, J. (1991). Alcohol and fatal injuries in Oklahoma. Journal of Studies on Alcohol, 52(2): 156-161.

Haines, M.A. (1996). Social Norms Approach to Preventing Binge Drinking at Colleges and Universities. Newton, MA: The Higher Education Center for Alcohol and Other Drug Prevention, Education Development Center, U.S. Department of Education. Pub. No. ED/OPE/96-18.

Harrington, N.T. \& Leitenberg L. (1994). Relationship between alcohol consumption and victim behaviors immediately preceding sexual aggression by an acquaintance. Violence and Victims $9(4): 315-324$.

Hingson, R. \& Howland, J. (1993). Alcohol and non-traffic unintended injuries. Addiction 88:877-883.

Johannessen, K., Collins, C., Mills-Novoa, B., \& Glider, P. (1999). A practical guide to alcohol abuse prevention: A campus case study in implementing social norms and environmental management approaches. Tucson, AZ: University of Arizona Campus Health Service.

Martin, S.E. (1992). Epidemiology of alcohol-related interpersonal violence. Alcohol Health and Research World, 16(3):230-237. 
National Highway Traffic Safety Administration. Traffic safety facts 1998: Alcohol. National Center for Statistics and Analysis. Washington DC. 1999.

Perkins, H.W. \& Berkowitz, A.D. (1986). Perceiving the Community Norms of Alcohol Use among Students: Some Research Implications for Campus Alcohol Education Programming. International Journal of the Addictions, 21: 961-976.

Perkins, H. Wesley \& Wechsler, Henry (1996). "Variation in Perceived College Drinking Norms and Its Impact on Alcohol Abuse: A Nationwide Study." Journal of Drug Issues, 26(4): 961-974.

Presley, C., Meilman, P., Cashin, J., and Leichliter, J. (1997). Alcohol and Drugs on American College Campuses: Issues of Violence and Harassment: A Report to College Presidents Southern Illinois University at Carbondale: Core Institute.

Roizen, Judith. (1997). Epidemiological issues in alcohol-violence. In Recent developments in alcoholism, vol. 13: Alcoholism and violence. Marc Galanter ed. New York: Plenum Press, pp.7-40.

Sleet, D.A., Wagenaar, A.C. \& Waller, PF. (1989).Introduction: Drinking, Driving and Health Promotion. Health Education Quarterly, 16: 329-333.

Smith, G.S., Branas, C.C. \& Miller, T.R. (1999). Fatal nontraffic injuries involving alcohol: A metaanalysis. Annals of Emergency Medicine, 33(6): 659-68.

Voas, R.B., Wells, J., Lestina, D., Williams, A. \& Greene, M. (1998). Drinking and driving in the United States: The 1996 National Roadside Survey. Accident Analysis and Prevention, 30(2):267-275.

Wechsler, H, Davenport, A, Dowdall, G, Moeykens, B. \& Castillo, S. (1994). Health and Behavioral Consequences of Binge Drinking in College: A National Survey of Students at 140 Campuses. JAMA, 272: $1672-1677$.

Wechsler, H., Dowdall, G.W., Maenner, G., Gledhill-Hoyt, J. \& Lee, H. (1998). Changes in binge drinking and related problems among. American college students between 1993 and 1997: Results of the Harvard School of Public Health College Alcohol Study. Journal of American College Health, 47 (2): 57-68.

Wechsler, H., Lee, J., Kuo, M. \& Lee, H. (2000). College Binge Drinking in the 1990s: A Continuing Problem - Results of the Harvard School of Public Health 1999 College Alcohol Study. Journal of American College Health, 48(10): 199-210.

Werch, C.E., Bakema, D., Ball, M., Lee, D., Munodawafa, D. \& Raub, M. (1988). Cataloging blood alcohol level and alcohol consumption data in field settings: Feasibility and findings. Journal of Studies on Alcohol, 49(6):561-566. 
Appendix 2.a. 1997 Interview Questionnaire 
How'd you get here tonight? Did you ride in a car, walk, or what?

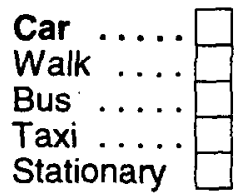

Motorcycle

Bicycle............

Point-to-Point

Drive?...

Other...
Interviewer ID

Driver $\square$

Time

Number males/females

Have you'all been together for at least the last hour?

YES $\square$ NO $\square$

Again I want to emphasize that this is completely voluntary and confidential. If we come to any question you don't want to answer, just let me know and we'll go on to the next one.

\section{Questions}

1. Are you a student here at UNC? YES $\square \quad$ NO $\square$

2. What year are you? Freshman $\square$, Sophomore $\square$, Junior $\square$, senior $\square$, 5th year or beyond $\square$, Graduate Student $\square$

3. How old are you?

4. Do you live here? $\quad$ YES $\square$ NO $\square>$ [IF NO] Where do you live?

5. Do you belong to a fraternity or sorority? YES $\square$ NO $\square$

6. What have you [y'all] been doing tonight?

7A. Have you been drinking tonight?

YES $\square$ NO $\square>$ TO QUESTION 7B

7B. [IF NO] Have you been out with friends who were drinking tonight?

8. What were you drinking tonight? (CHECK ALL THAT APPLY)

(PROMPT: anything else?)

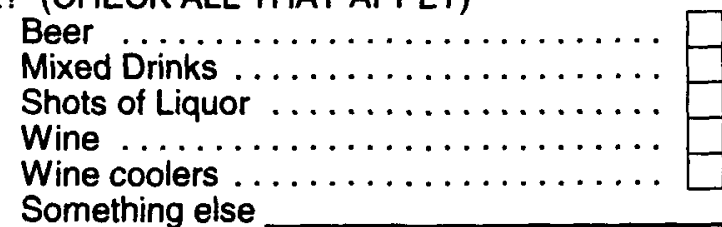

9. How do you feel right now? Would you say sober, a little buzzed, pretty drunk, or wasted?

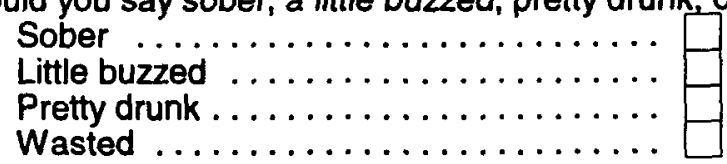

10. About what time did you have your first drink tonight?

11. Where were you when you had your first drink tonight? (Did you drink anywhere else this evening?)

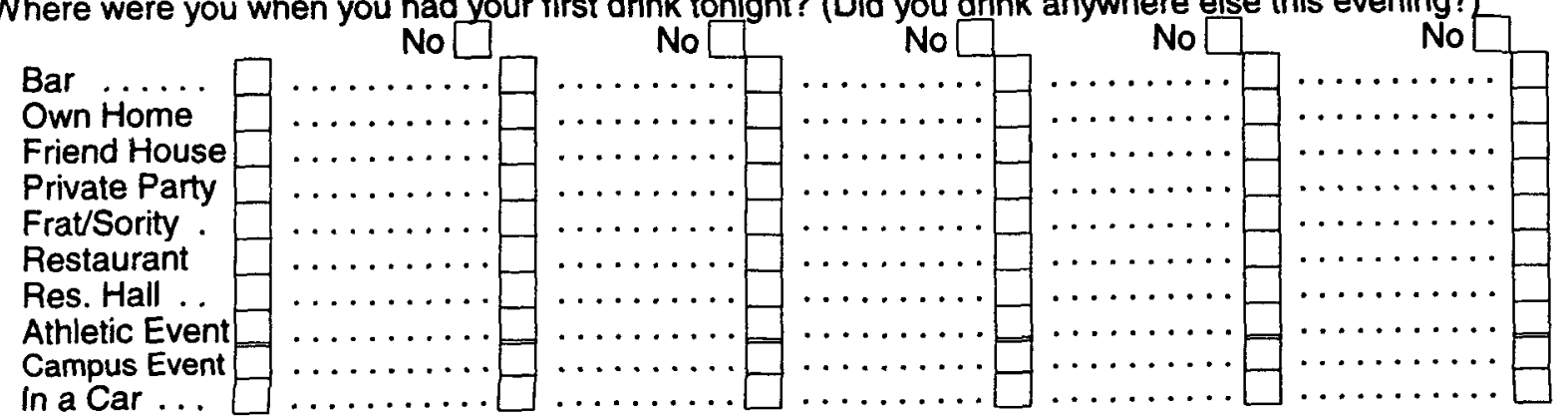

Other 
13. About how long ago did finish your last drink? Hrs.

Min.

14. About how many drinks would you say you had tonight?

ARRIVED IN A CAR, MOTORCYCLE >

PASSENGER IN A CAR >

DRIVER OR OTHER THAN > CAR
15A. Did you have a designated driver tonight?

15B. How did you decide who would drive tonight?

15C. [IF DRIVER] Were you the designated driver?
YES $\square$ NO $\square$

YES $\square$ NO $\square$

16A. Would you say the Blood Alcohol Level of the DRIVER in your group was higher, lower, or about the same as your's?
Higher ......
Lower ......
Same ......
Don't know ...

16B. Would you say the Blood Alcohol Level of the others in your group was higher, lower, or about the same as your's?

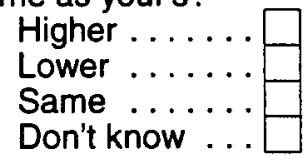

Some Higher/Some Lower

17. In general, would you say that you drink more, less, or the same as the typical student on this campus?

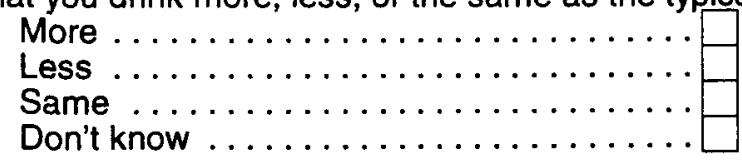

18. Now l'd like you to think back over the last two weeks. About how many times would you say you had five or more drinks in a row?

19. Have you experienced any of the following this evening: (CHECK ALL THAT APPLY)

$$
\begin{aligned}
& \text { had to take care of a friend that drank too much } \ldots \ldots \\
& \text { got nauseated or vomited } \ldots \ldots \ldots \ldots \ldots \ldots \ldots \ldots \\
& \text { got into an argument or fight } \ldots \ldots \ldots \ldots \ldots \ldots \\
& \text { trouble with police, residence hall, or other authorities } \\
& \text { been hurt or injured } \ldots \ldots \ldots \ldots \ldots \ldots \\
& \text { or any other type of problem not listed? }
\end{aligned}
$$

20. If you were to guess, what would you say your blood alcohol level is right now? Using this scale, from zero to .24 , where 0.08 is the legal limit for drivers.

21. Now, there's one more thing I need to do. Again, your participation is voluntary. This is a device....

\section{Observations/Comments}

1. BAC

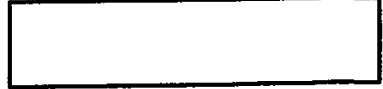

Refused ....

2. SEX
Male .......

Female .....
3. RACE

Black ......
White ....
Other .... .

Refused Comments
Evidence of alcohol use $\mathrm{Y} / \mathrm{N}$ 
Appendix 4.a. 1999 Interview Questionnaire 
1. How'd you get here tonight? Did you ride in a car, walk, or what?<smiles>CC(C)(Br)C1(C(Br)(Br)Br)CCC1</smiles>

Were you the driver or passenger? Driver $\square$ Passenger $\square$
Interviewer ID (Initials + Number)

Time End

Location

\section{Number Males/Fomales.}

II. Have y'all been together for at least the last hour? YES $\square$ NO $\square$

Again, I want to emphasize that this is completely voluntary and confidential. If we come to any question you don't want to answer, just let me know and we'll go on to the next one.

\section{Questions}

1. Are you a student here at UNC? YES $\square \quad$ NO $\square$

2. What year are you? Freshman $\square$ Sophomore $\square$ Junior $\square$ Senior $\square \quad 5^{\text {th }}$ year or beyond $\square$ Grad Student $\square$

3. How old are you?

4. Do you live here at [current location]? YES $\square$ NO $\square>$ [IF NO] Where do you live?

Out of Town.

CH/Carr. Area

5. Do you belong to a fraternity or sorority? YES $\square$ NO $\square$

Greek House.

UNC Dorm

6. Do you play a sport on an organized team? $\quad$ YES $\square \quad$ NO $\square$

7. In the last two weeks, have you....

Exercised or worked out? ..................

Attended a play, concert, or other arts performance?

Attended a religious service?

8. What have y'all been doing tonight?

9. Have you been drinking tonight? YES $\square$ NO $\square>$ [IF NO] Have you been with friends who were drinking tonight?

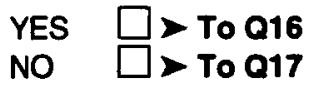

10. What were you drinking tonight? (CHECK ALL THAT APPLY)

(Anything else?)

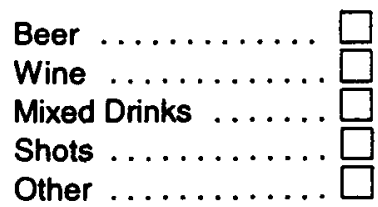

11. How do you feel right now? Would you say sober, a little buzzed, pretty drunk, or wasted?

Sober

A little buzzed

Pretty drunk

Wasted

12. About what time did you have your first drink tonight?

13. Where were you when you had your first drink tonight?

(Did you drink anywhere else this evening?)

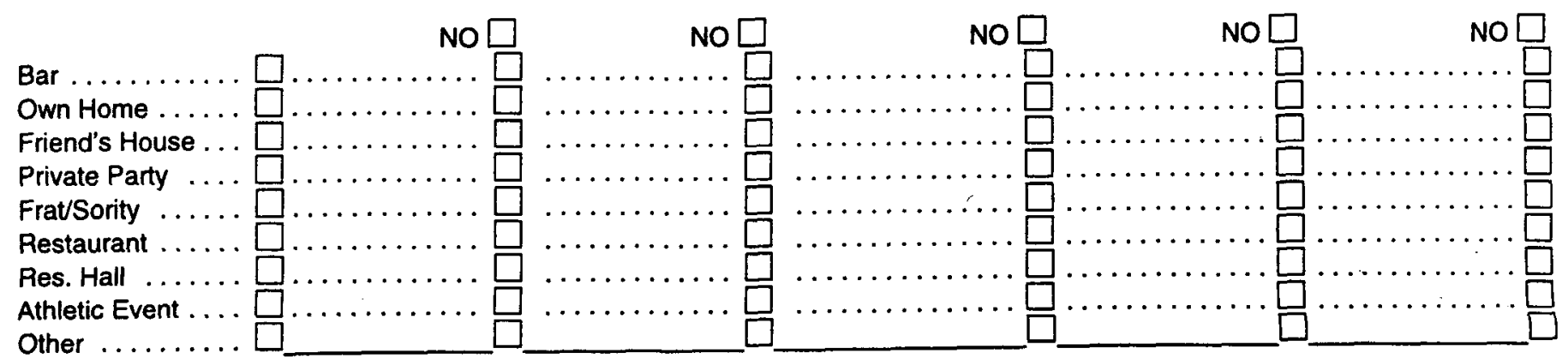

14. About how long ago did you finish your last drink?

Hrs

Min

15. About how many drinks would you say you had tonight? 


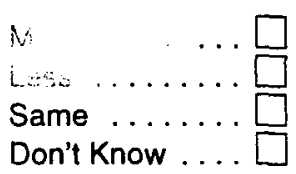

18. Now l'd like you to think back over the last two weeks.

About how many times would you say you had 5 or more drinks in a row?

19. Over these last two weeks, on how many days did you have anything alcoholic to drink? (If ZERO, TO Q21)

20. On those days that you drank, how many drinks did you usually have?

21. How old were you when you first began drinking, more than a few sips?

22. Compared to your last year of high school, how has your drinking changed?

Would you say, You Drink More Now, Less Now, or the Same?

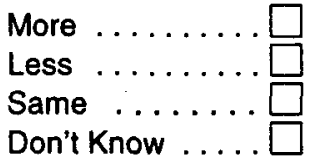

23. How important would you say alcohol is to students at UNC? Would you say, Very Important, Somewhat Important, or Not Very Important?

Very Important . . . . . . .
Somewhat Important . . . .
Not Very Important . . . . .
Don't Know $\ldots \ldots \ldots$

24A. Have you heard about the 2 out of 3 alcohol campaign?

NO .. $\square>$ To Q25

YES. $\square$ 24B. How did you hear about the 2 out of 3 campaign? (CHECK ALL THAT APPLY)

Posters .......... $\square$
Stickers . . . . . . . . $\square$
Newspaper Ads . . . $\square$

Other
C-TOPS .......

Prize Patrol. . ...

Fallfest .......
Web Page .....

On TV .........

From a Friend.

24C. What do you think the message of the campaign means?

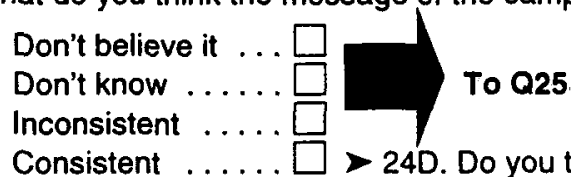

Consistent ........

24D. Do you think the 2 out of 3 fact accurately represents student drinking at UNC?

25. If you were to guess, what would you say your blood alcohol level is right now?

Using this scale, from zero to .24 , where .08 is the legal limit for drivers.

26. Now, there's one more thing I need to do. Again, your participation is voluntary. This is a device...

27. Observations (to be completed for ALL sampled individuals)

Sex $\quad$ Male ........ $\square$

\section{Evidence of Alcohol Consumption} NO EVIDENCE Open Can(s) or Bottle(s) ........ Unopened Can(s) or Bottle(s) . . . . . . Cups w/Possible Alcohol Prior Participation in Study None Mentioned $\square$
Race

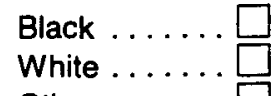

Other ....... $\square$

Admitted Drinking .... Slurred Speech ...... . Stumbling . . . . . . . . . . Odor.............
Refused All Participation

Reason

Comments, including additional evidence of alcohol 
DOT HS 809396

January 2001

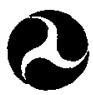

U.S. Department of Transportation

Notional Highwoy

Trafile Sofety

Administration 